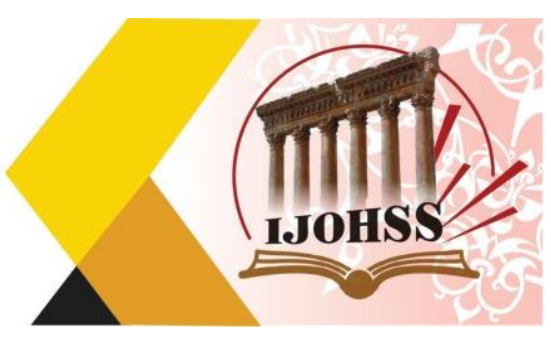

\title{
أثر انموذج فينك في تحصيل مادة العَروض عند طلبة قسم اللغة العربية في كليات التربية الأساسية
}

\author{
م. د. حسن فهذ عواد الأوسي \\ المديرية العامة لتربية محافظة ديالَى \\ وزارة التربية \\ العراق العزية \\ hassanfa02@gmail.com
}

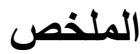

يهدف البحث إلى معرفة أثر انموذج فينك في التعلم النشط في تحصيل مادة العَروض عند طلبة قسم اللغة العربية في كليات التربية الأساسية ، و لتحقيق هدف البحث صاغ الباحث الفرضية الصفرية ( لا يوجد فرق ذو دلالة

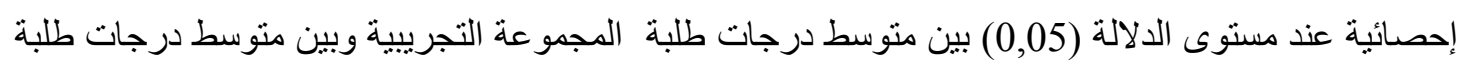
المجموعة الضابطة في اختبار التحصيل).

اعتمد الباحث المنهج التجريبي منهجاً لبحثه والتصميم التجريبي تصميما له، تحدد مجتمع البحث بطلبة المرحلة الثانية في قسم اللغة العربية في كليات التربية الأساسية / الدراسة الصباحية في الجامعات العر اقية للعام الدراسي 2018-2019 ، اختار الباحث قصدياً كلية التربية الأساسية / الجامعة المستتصرية عينة لبحثه وكافأ بين

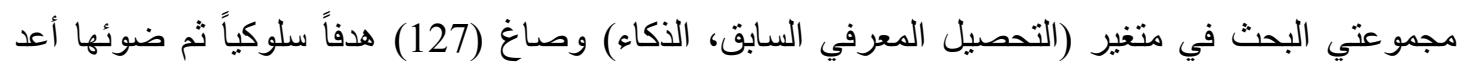
اختباراً تحصيلياً أداة لبحثه وبعد نطبيقه أظهرت نتيجة البحث وجود فرق دال إحصائياً لمصلحة المجموعة فئاء التجرييية وبناءً على ذلك قدم الباحث العديد من الاستنتاجات و التوصيات و المقترحات. 


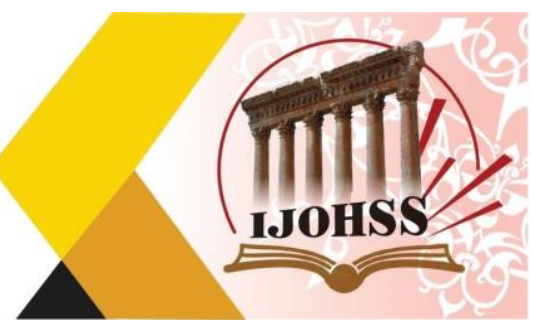

\title{
The effect of the Fink model on the achievement of the presentation subject among students of the Arabic Language Department in the Faculties of Basic Education
}

\author{
Dr. Hassan Fahd Awwad Al-Awsi \\ Directorate General of Education Diyala Governorate \\ Ministry of Eduction \\ Iraq \\ hassanfa02@gmail.com
}

\begin{abstract}
The research aims to know the effect of the Fink model on active learning on the achievement of the presentation material among students of the Arabic Language Department in the Faculties of Basic Education, and to achieve the goal of the research, the researcher formulated the null hypothesis (there is no statistically significant difference at the level of significance (0.05) between the average score The experimental group students and the average scores of the control group students in the achievement test).

The researcher adopted the experimental approach as an approach for his research and experimental design, in order to design his research, the current research community is determined by the second stage students in the Arabic language department in the Faculties of Basic Education / Morning Studies in Iraqi universities for the academic year 2018-2019. The research rewarded the two groups of research in a variable (previous cognitive achievement, intelligence) and (127) behavioral goals were formulated and in the light of which an achievement test was prepared as a tool for his research, and after its application, the results of the research showed a statistically significant difference in favor of the experimental group, and accordingly the researcher presented many conclusions, recommendations and proposals .
\end{abstract}

Keywords: Fink Model, Presentation Course, Department of Arabic Language, Colleges of Basic Education.. 


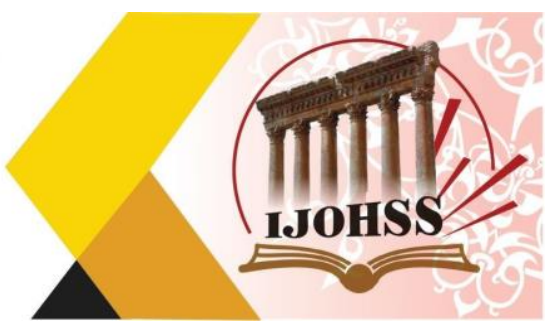

\section{الفصل الاول \\ التعريف بالبحث}

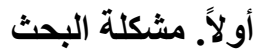

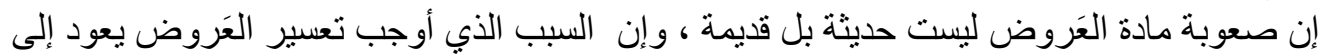

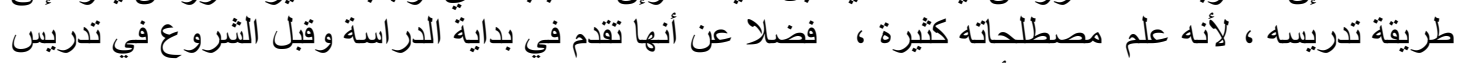

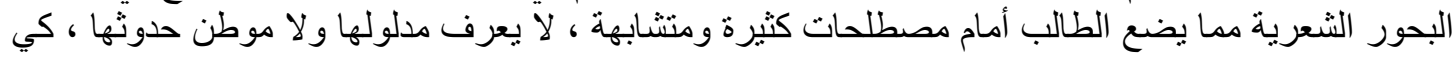

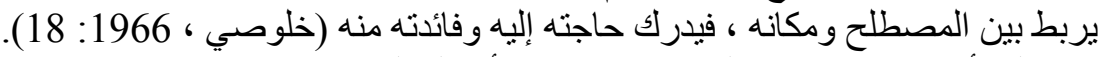

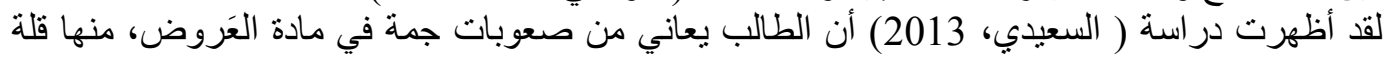

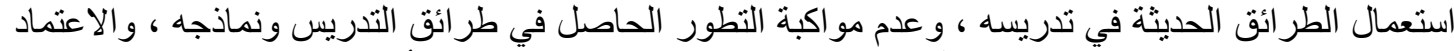

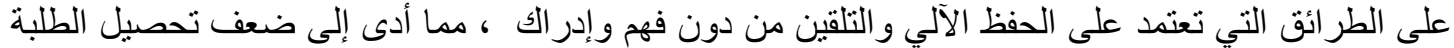
فيه ( السعيدي، 2013: 138 138).

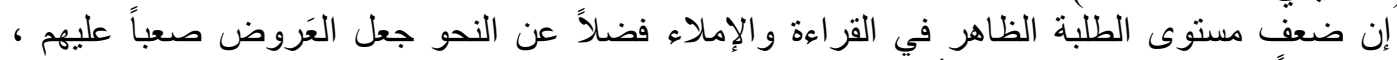

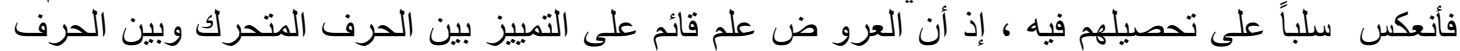

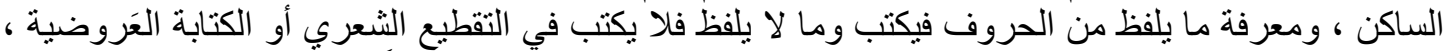

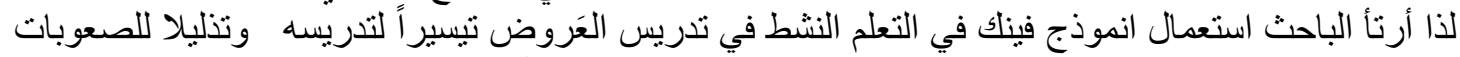

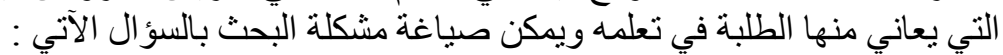

(هل لأنموذج فينك في ألتعم النشط أثر في تحصيل طلبة قسم اللغة فئة العربية في كليات التربية الأساسية ؟ ؟ )

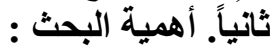

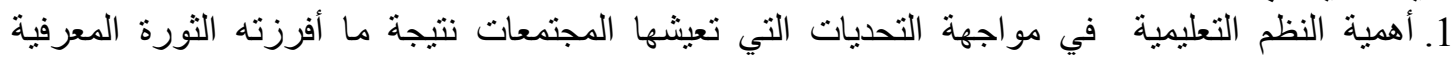

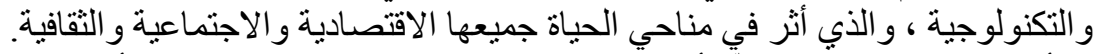

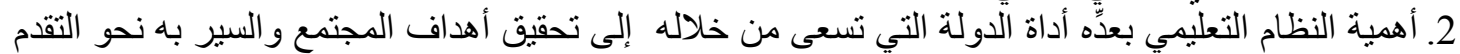

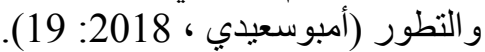

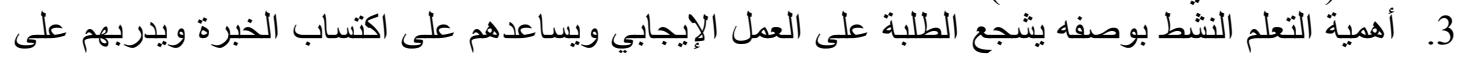

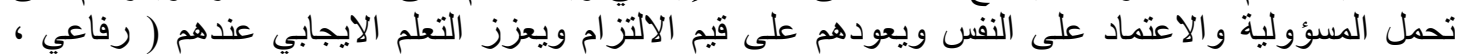
4. أهمية اللغة العربية بعدّها لغة القرآن ولغة آلغرة العرب .

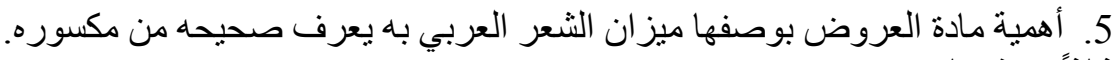

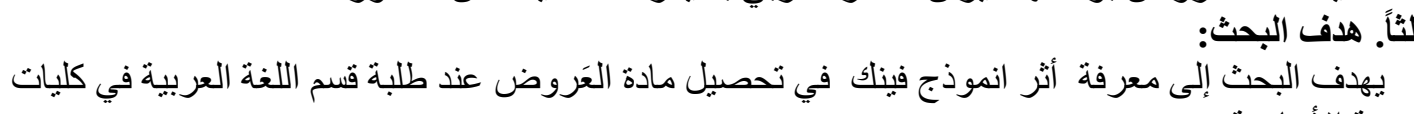
التربية الأساسية .

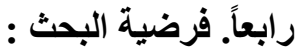

لتحقيق هدف البحث صاغ الباحث : الباغ الفرضية الصفرية الآتية :

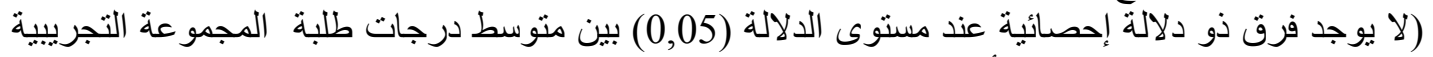

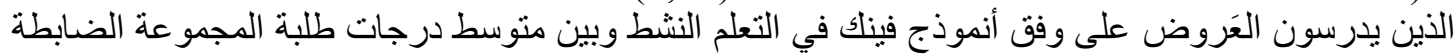
الذين يدرسون العَروض على على وفق وضى الطريقة التقليدية في اختبار التحصيل). خامساً. حدود البحث : البروض

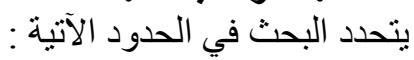
1. الحد البشري : طلبة المرحلة الثانية قسم اللغة العربية في كليات التربية الأساسية / الجامعة المستنصرية .

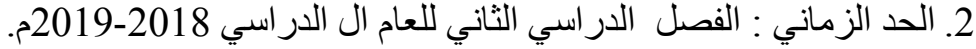
3. الحد المعرفي : موضوعات : الزعادة العَروض المقررة : ( بحر الخفيف ، بحر المجتث ، بحر السريع ، بحر

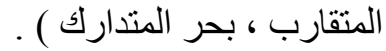




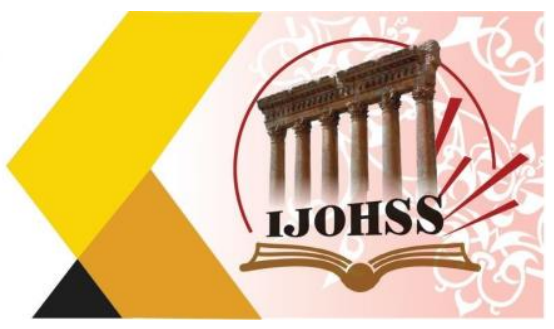

سادساً. تحديد المصطلحات :

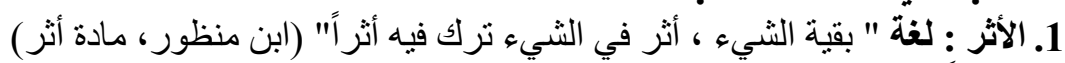

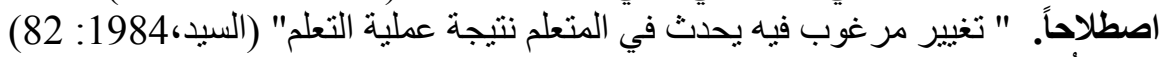

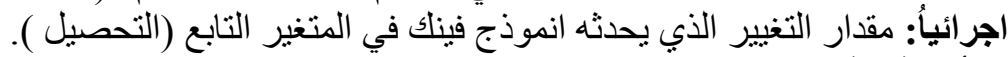

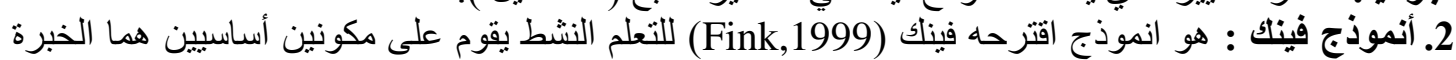

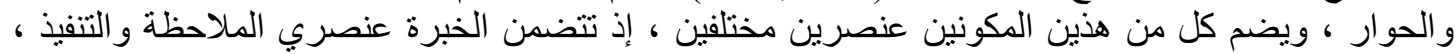

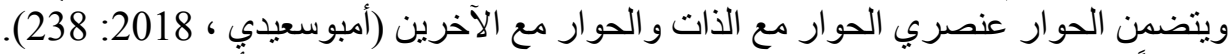

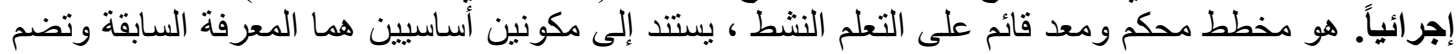

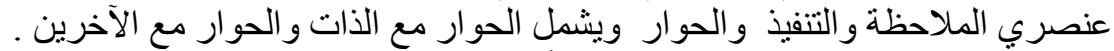

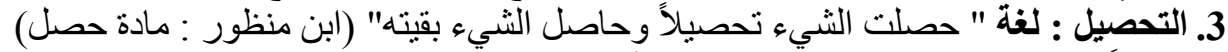

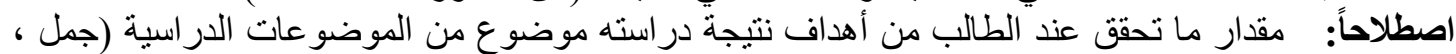

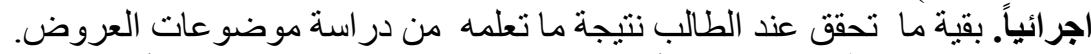

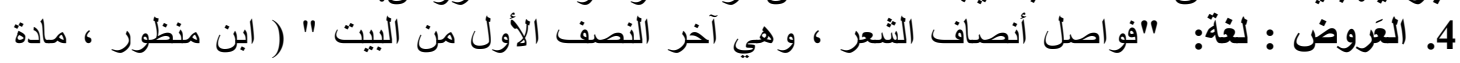
اصطلاحاً: "علم يعرف به صحيح وزن الثعر من فاسده ، و المنكسر فيه وما يدخله من زحافات و علل" (فضل، ولهن (15: 2015 اجرائياً: : هو مادة مقررة في قسم اللغة العربية / كليات التربية الأساسية تعنى بدراسة ميزان الثعر العربي وما

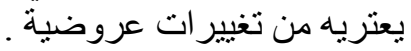

$$
\text { جوانب نظرية ودراستات سابقة الثاني }
$$

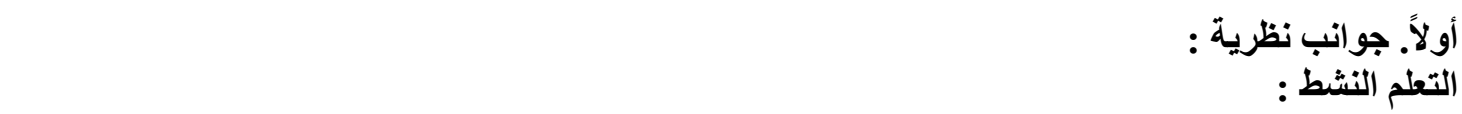
يعتمد التعلم النشط على ايجابية المتعلم في الموقف التعليمي ، ويهدف الى تفعيل دوره عبر العمل و البحث

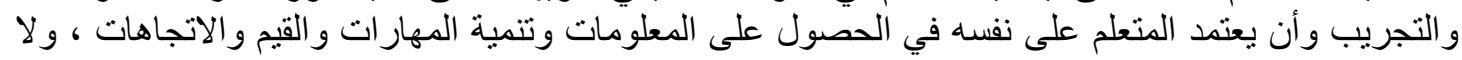

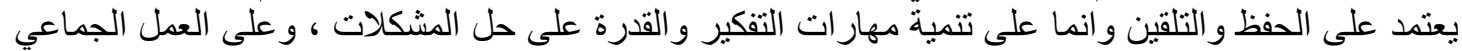

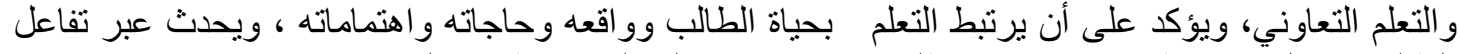

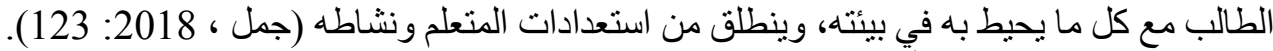

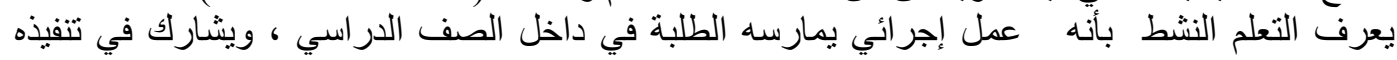

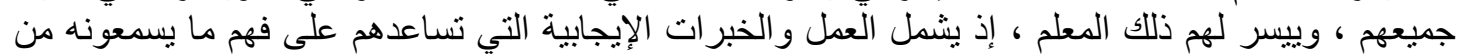

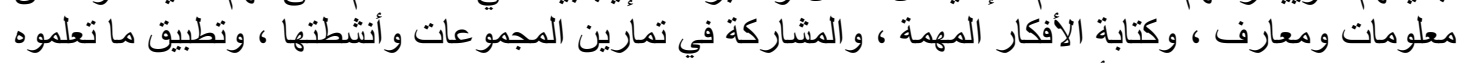

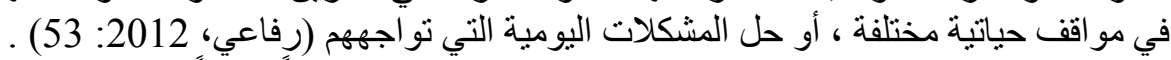

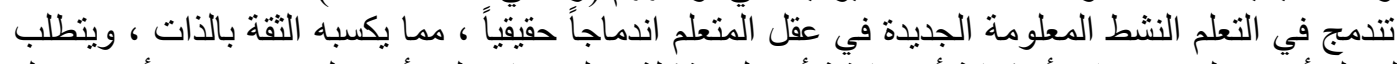

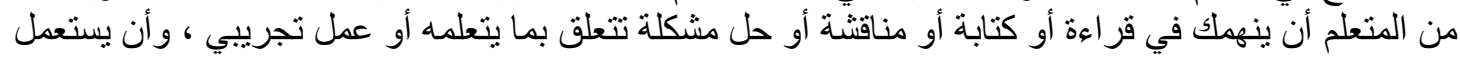

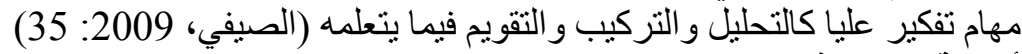
أنثطة المتعلم في التعلم النشط: (الصيفي ،2009: 235)

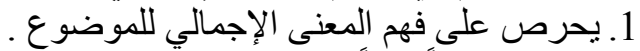
2. يخصص وقتاً كافياً للتفكير بأهمية ما يتعلمه.

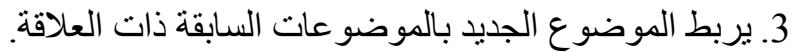
4. يربط الأفكار الجديدة بمواقف الحياة التي بمكن أن تنطبق عليه . 


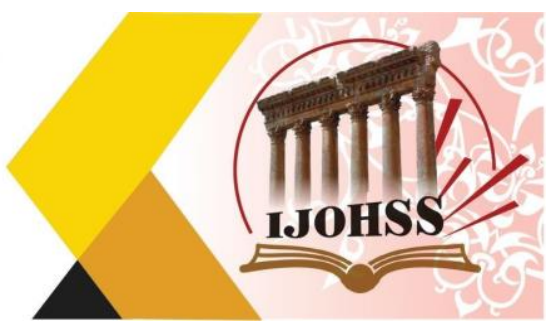

5. يحاول أن بربط بين الأفكار في مادة ما وبين و الأفكار المقابلة في المو اد الأخرى .

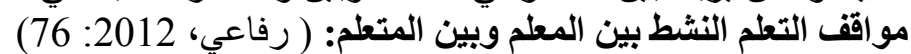
يمكن للمعلم تطوير مو اقف التعلم النشط باستمر ار عبن عبر ما يأني : 1. تشجيع دافعية الطلبة ومساعدنهم على الفئ التعلم.

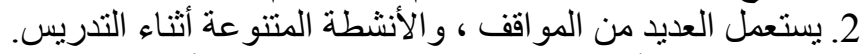

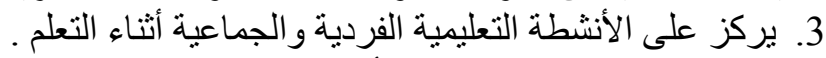

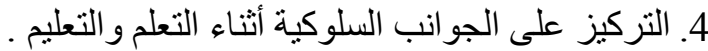
5. إتاحة الفرصة للنقاشـات الطلابية أثناء التعلم النشط.

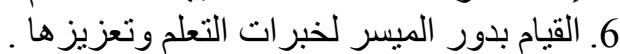

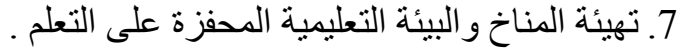

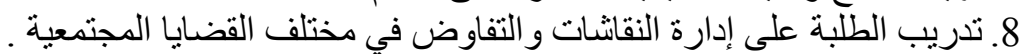

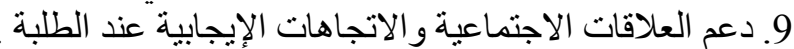

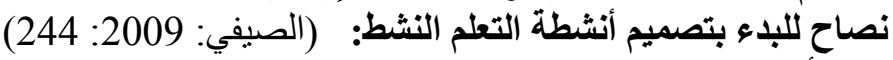

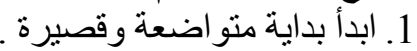

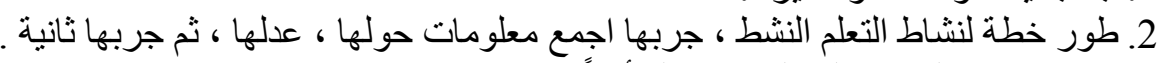
3. جرب ما ستطلبه من المتعلمين بنفسك أو أولاً. 4. شكل أزواج عشو ائية من المتعلمين في الأنشطة.

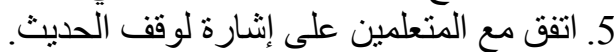
6. إن التفكير و التأمل في الممارسات التنارة التدريسية ومنابعة الجديد شرط للنجاح

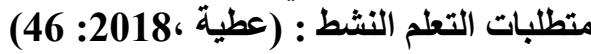

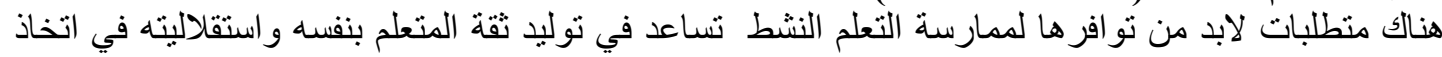

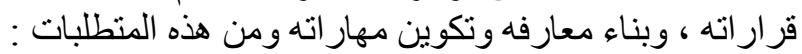

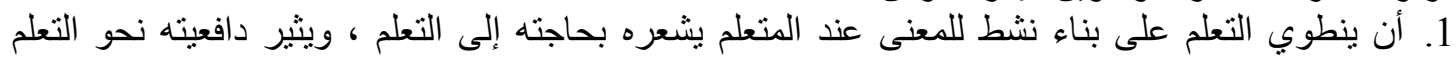
و المشاركة في عملية التعلم . 2. أن بربط بين الحقائق والخبرات التي يتعلمها وإجر اءات تطبيقها بالواقع ، لكي يستعطها في حل المشكلات التي تو اجهها. 3. أن يمكن المتعلم من نقل المعارف و الخبرات التي يتعلمها إلى مو اقف جديدة في حياته.

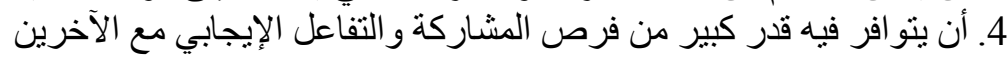

نموذج فينك في التعلم النشط :

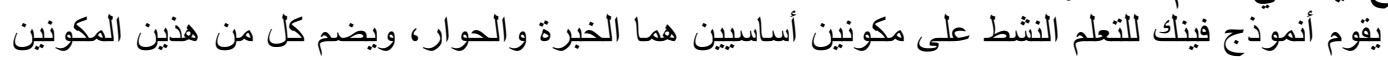

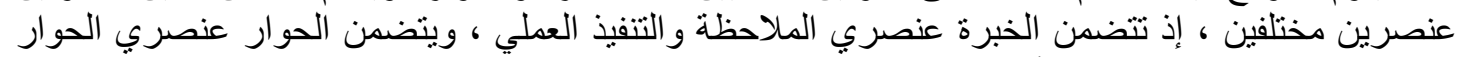
مع الذات و الحوار مع الآخرين (أمبو سعيدي، عندئ 2018: 238). 

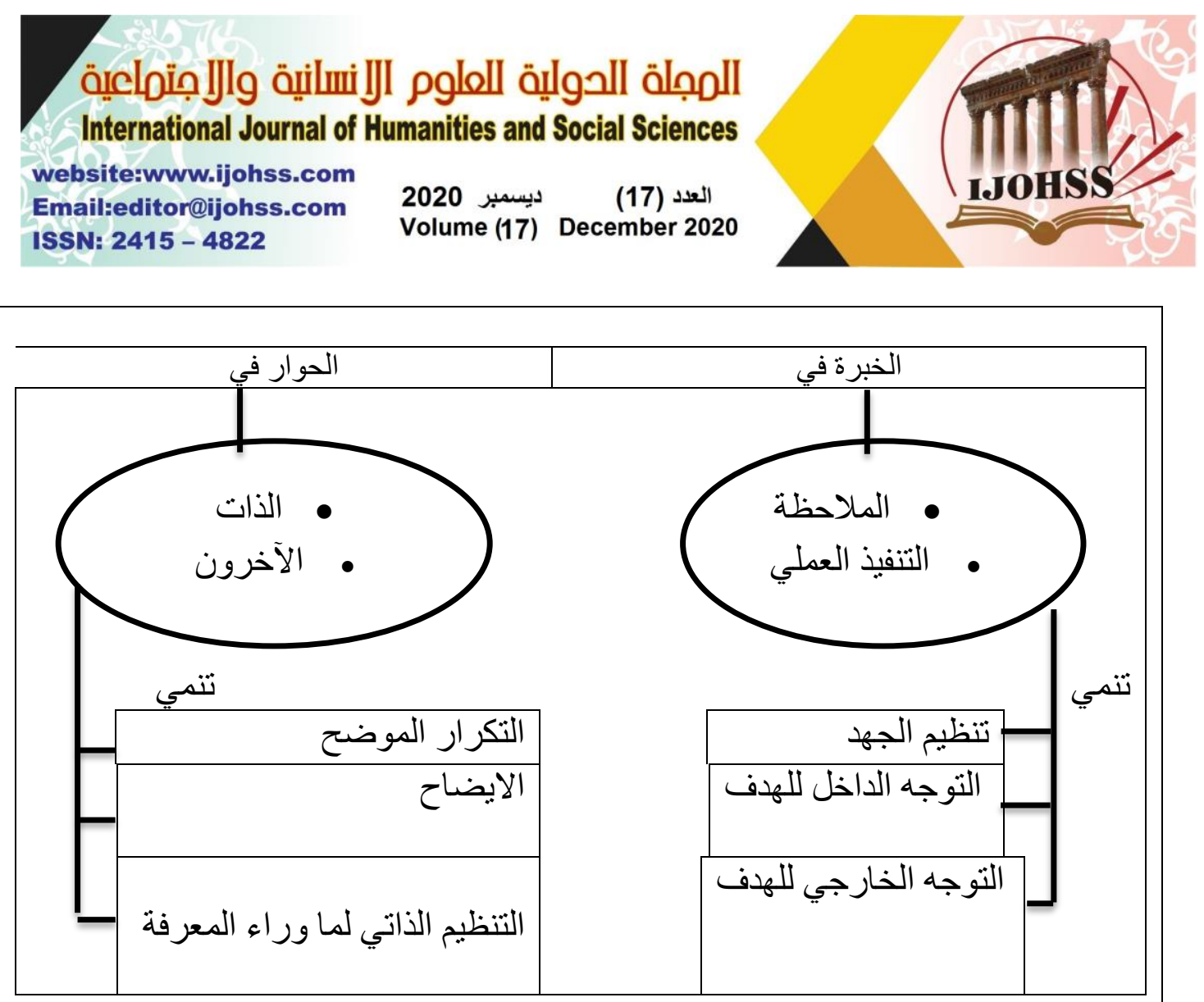

شكل (1)

نموذج فينك (Fink,1999) للتعلم النشط (1أمبوسعيدي،2018: 239)

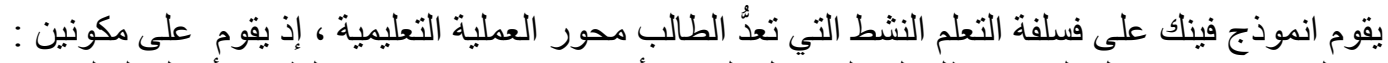

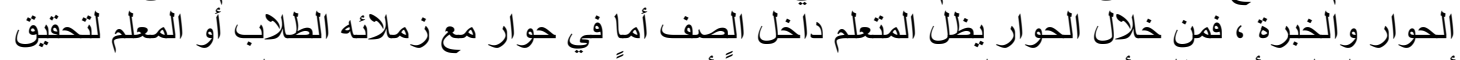

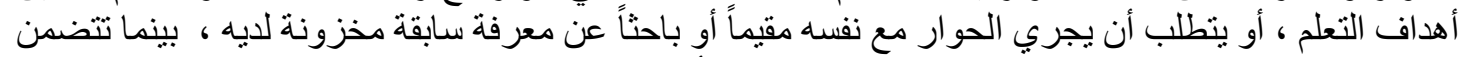

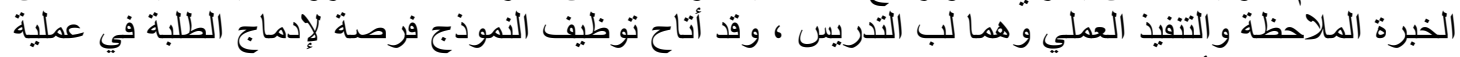

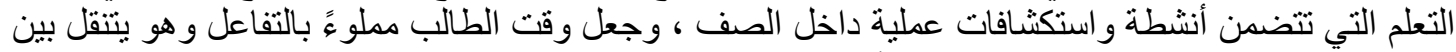

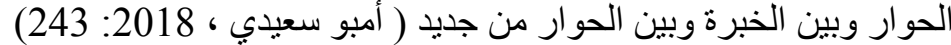

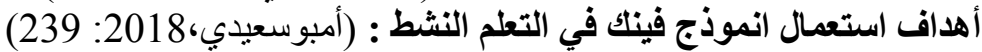

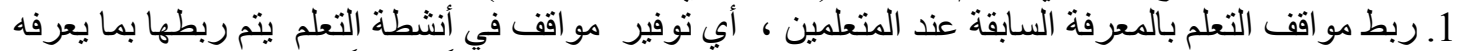

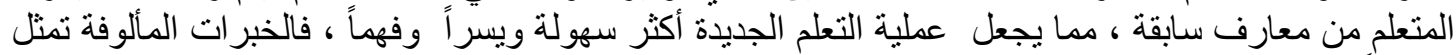

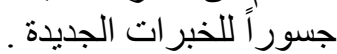

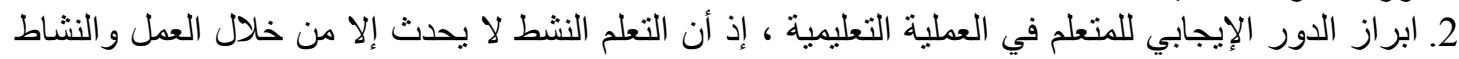

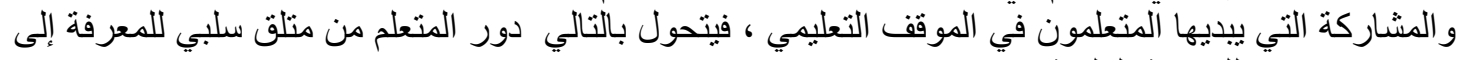

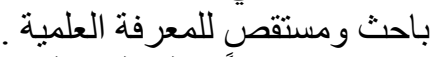

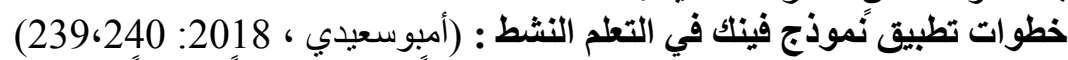

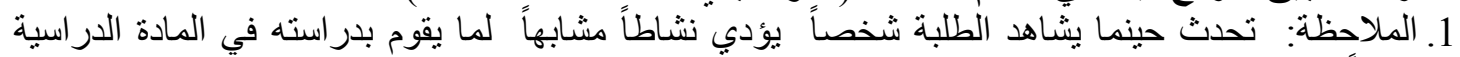

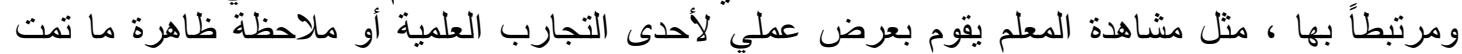

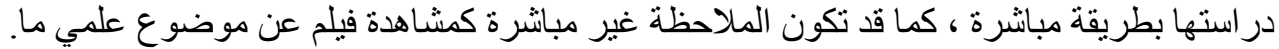

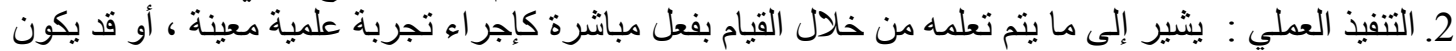

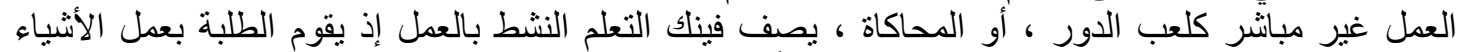

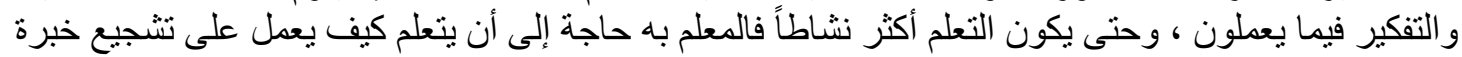

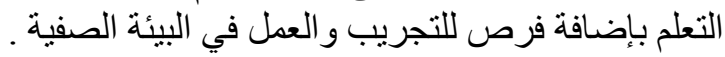




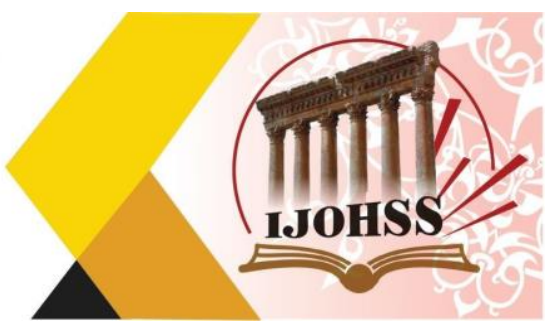

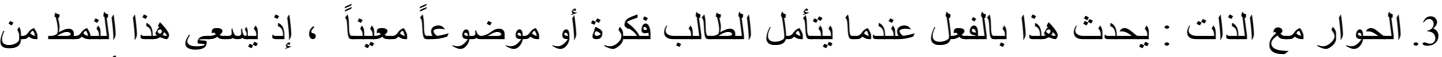

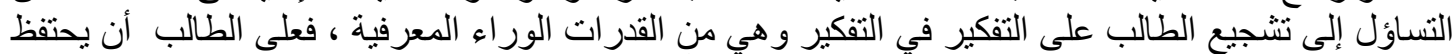

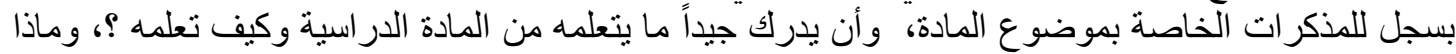

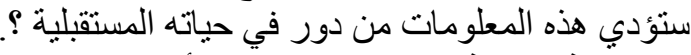

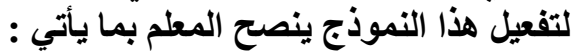

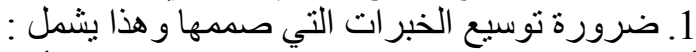

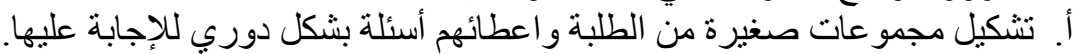

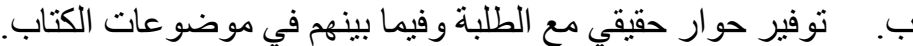

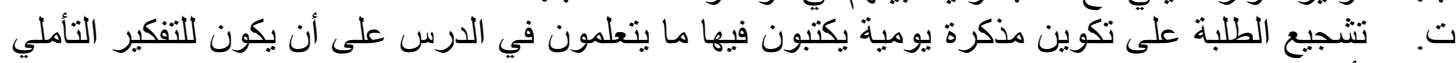
مساحة أكبر فيها.

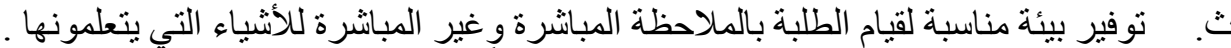

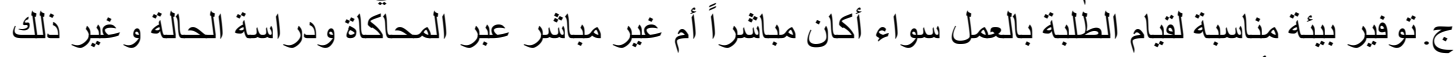
من الطرق و الأساليب.

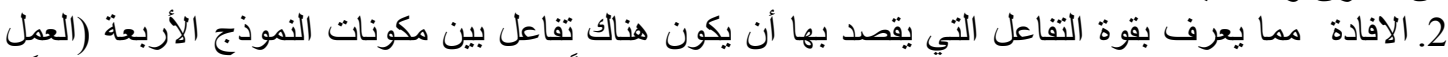

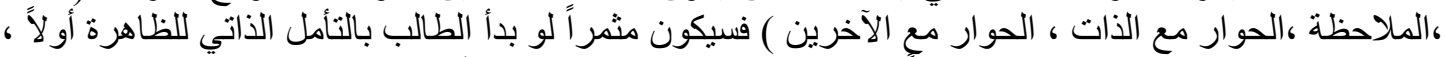

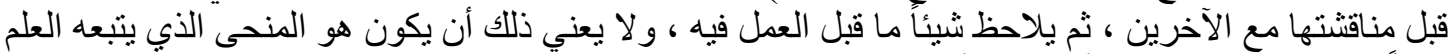

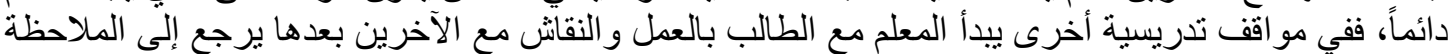

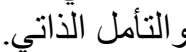

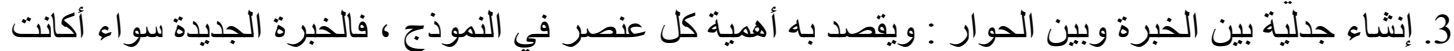

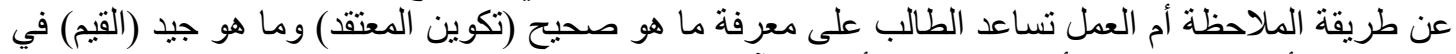

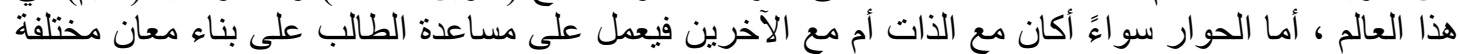

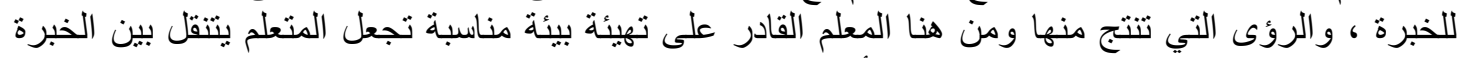

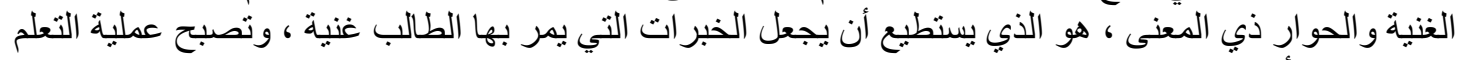

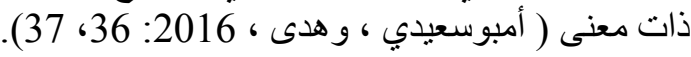

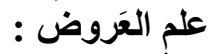

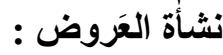

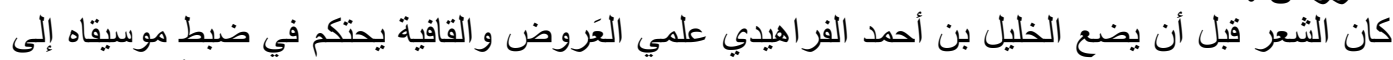

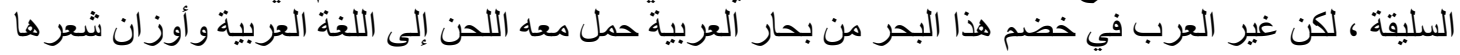

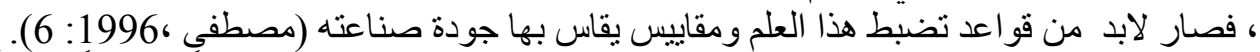

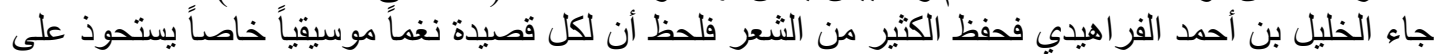

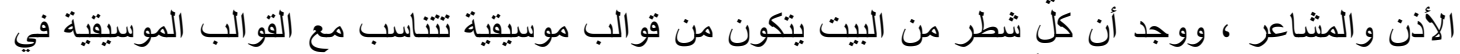

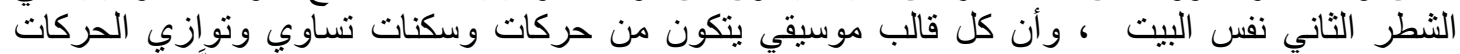

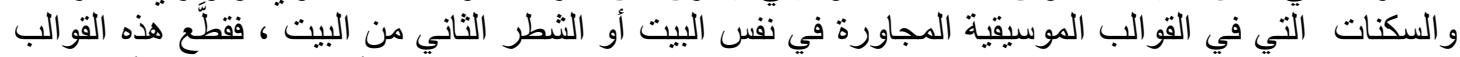

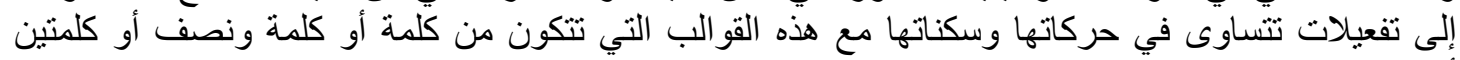

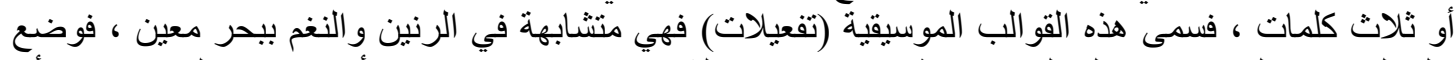

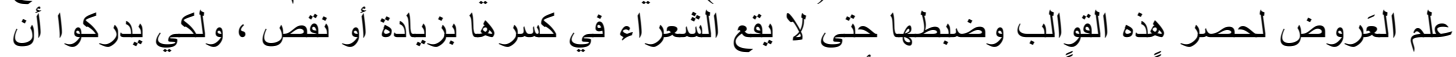

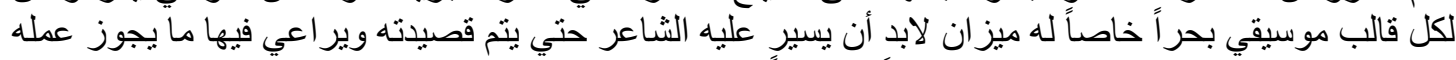

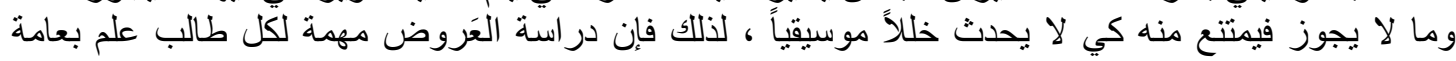

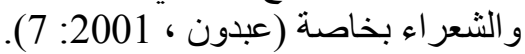
العلاقة بين العروض وبين الثعر: الثراه

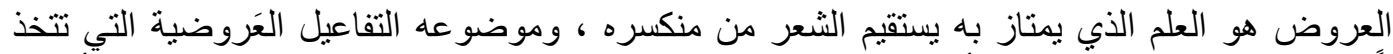

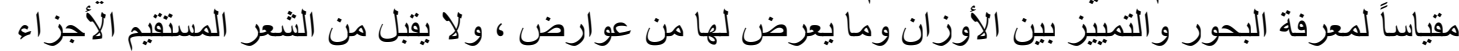

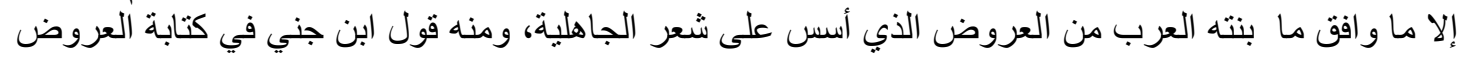




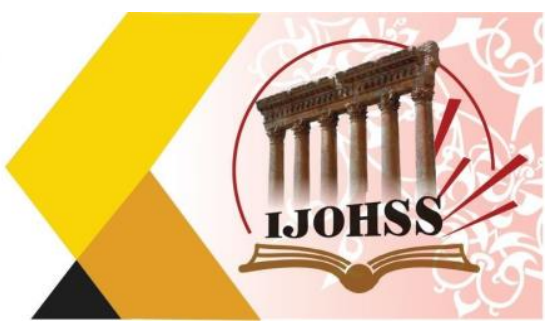

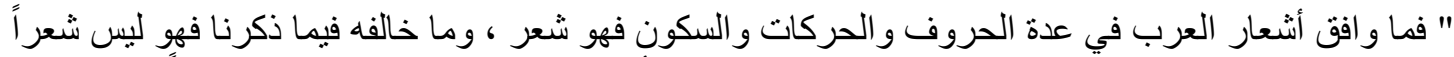

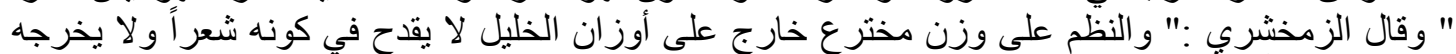

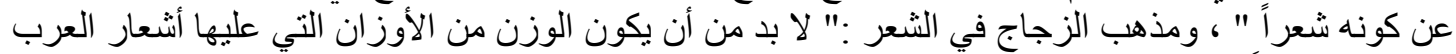

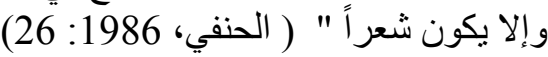

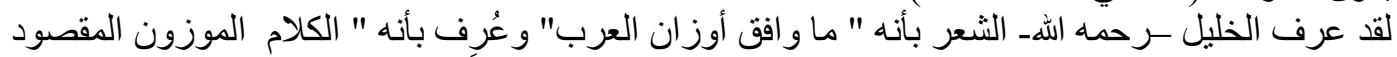

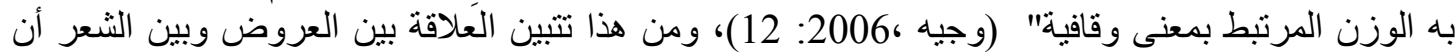

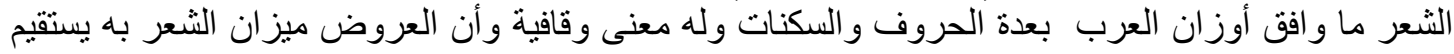

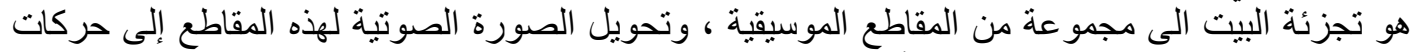

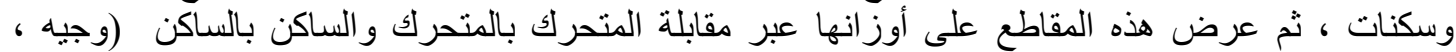

التفعيلات : هي المقياس العروضي الذي تقاس به أبعاد أجز اء البيت وبتلاقي التفعيلات يعرف نون نوع البحر

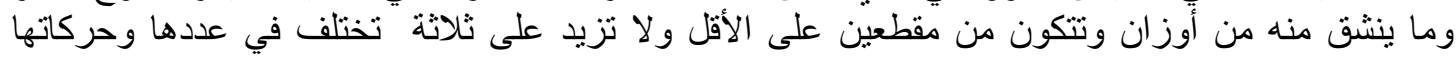

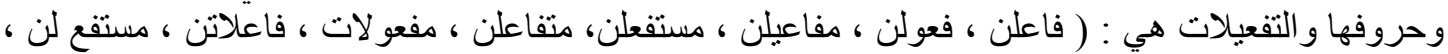

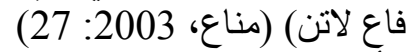

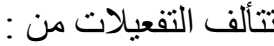
1. السبب : مقطع عروضي يتألف من حرفين و هو نو عان :

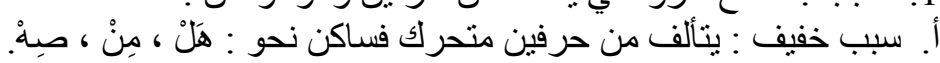

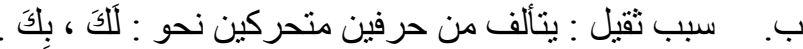

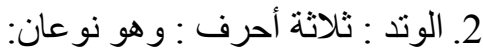

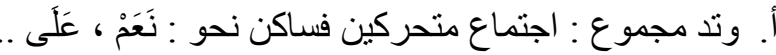

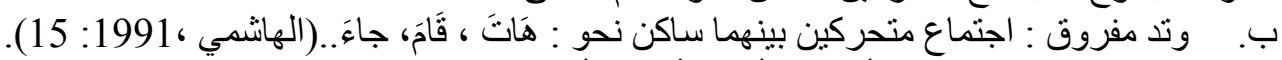

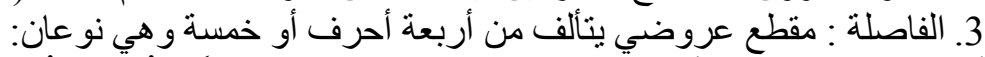

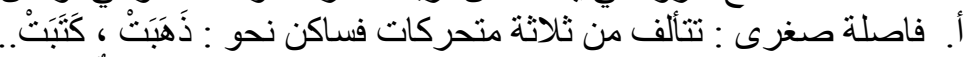

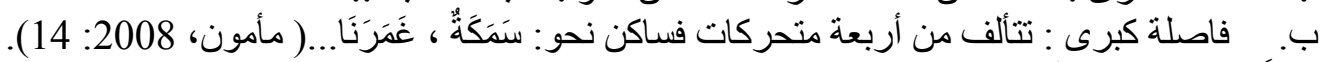

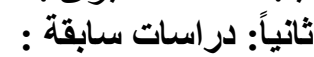
1. دراسات تناولت المتغير المستقل (انموذج فينك في التعلم النشط) : دراسنة

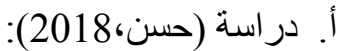

هدف البحث إلى معرفة أثر " أنموذج فينك في التفكير الجانبي وتحصيل الصف الأول في قسم الحاسبات "

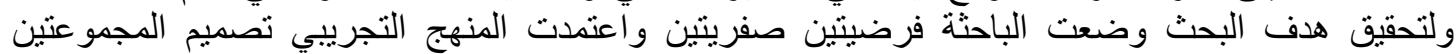

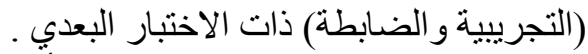

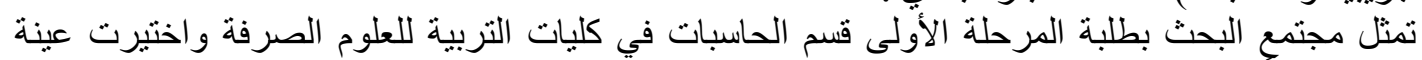

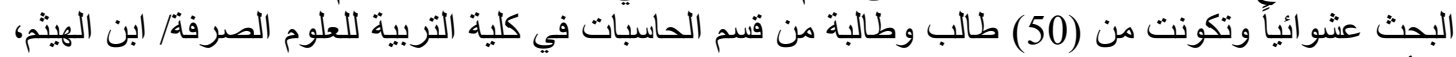

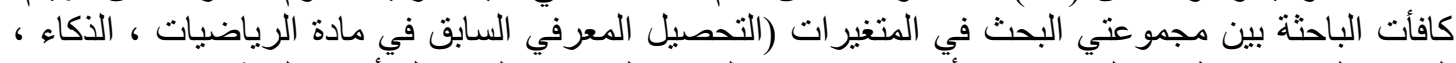

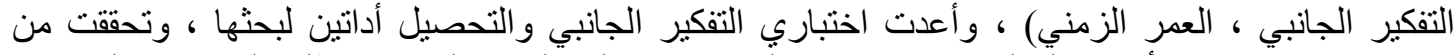

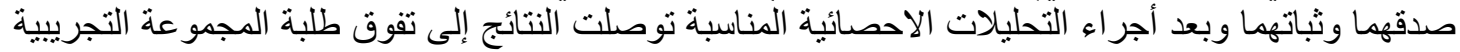
الذين درسوا على وفق انموذج فينك على طلبة المجموعة الضابطة في اختباري التفكير الجانبي والتحصيل(

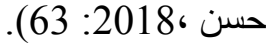

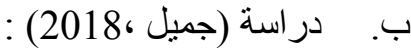

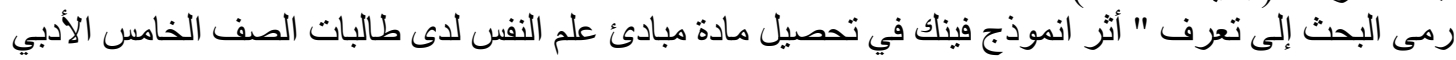

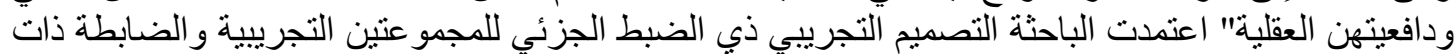




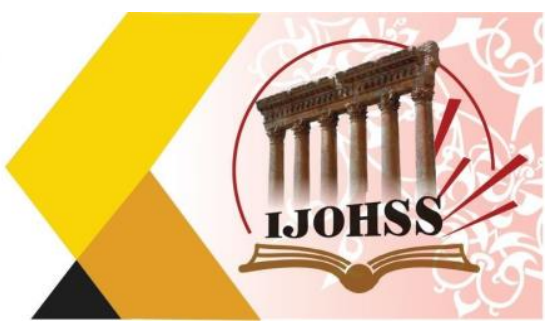

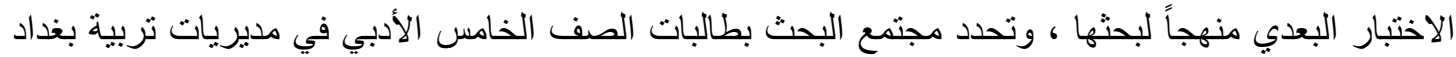

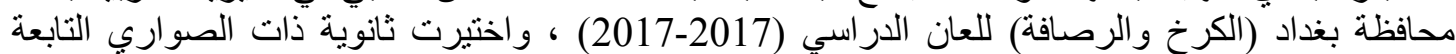

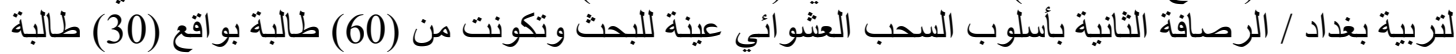

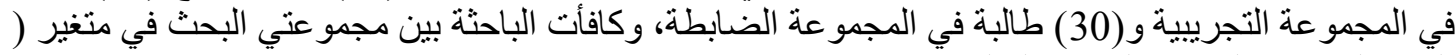
العمر الزمني ، الذكاء ، الدافعية العقلية).

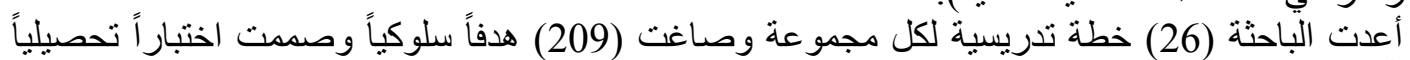

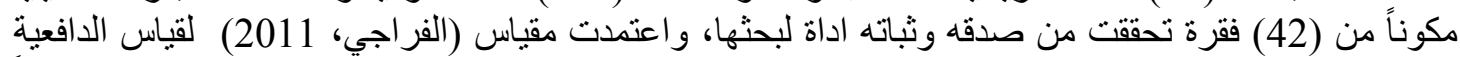

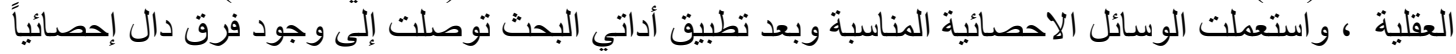

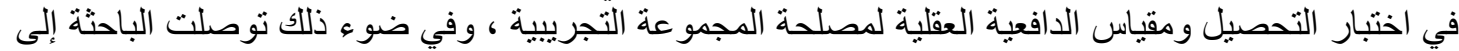

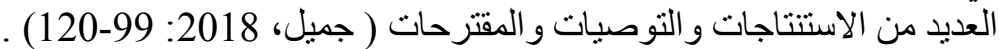

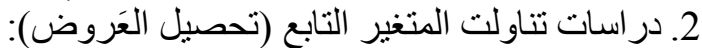

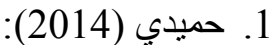

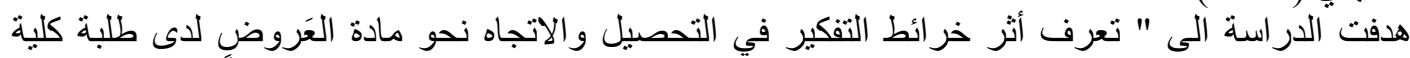

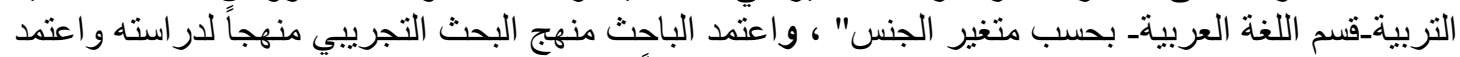

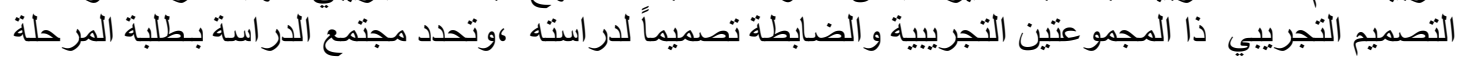

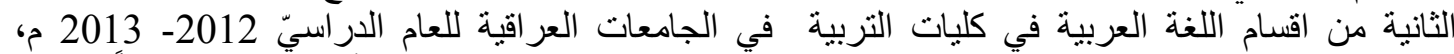

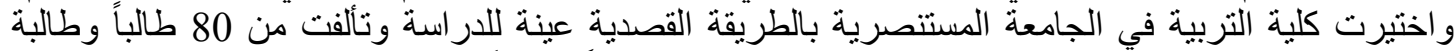

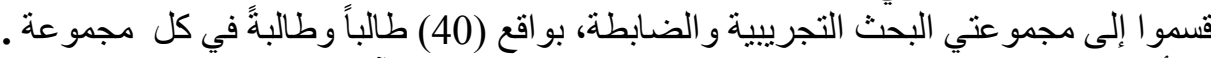

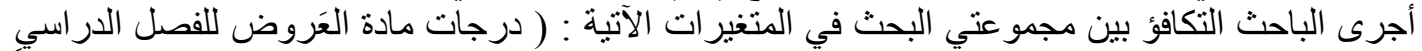

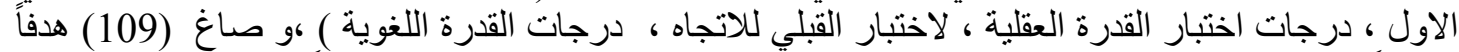

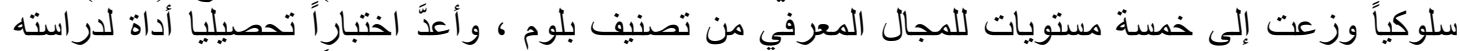

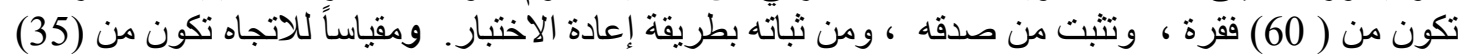

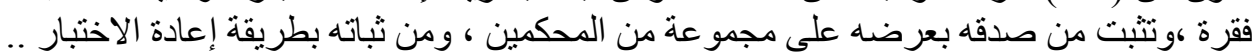

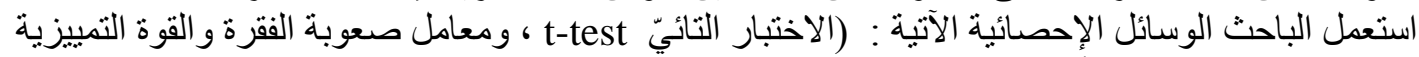

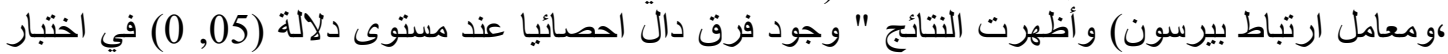

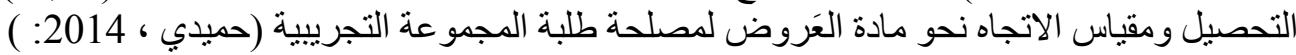

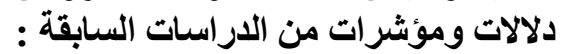

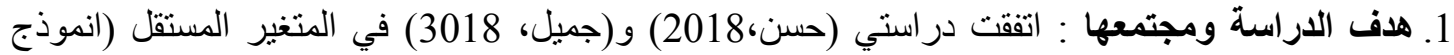

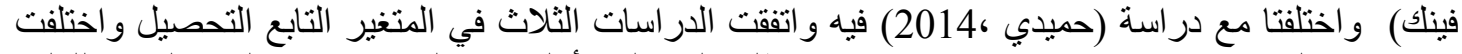

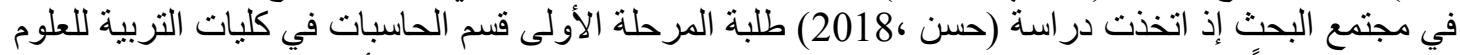

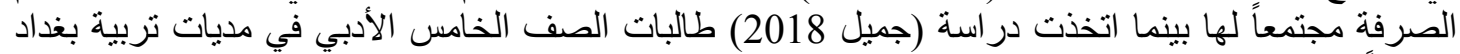

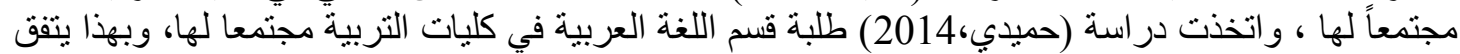

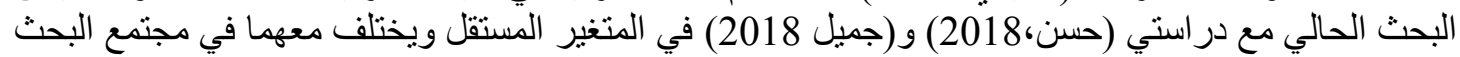

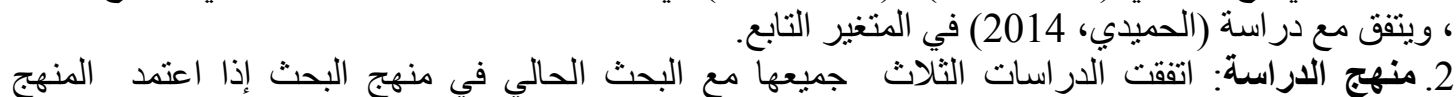

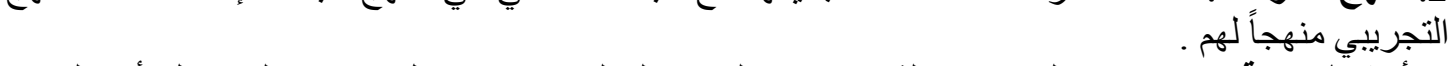

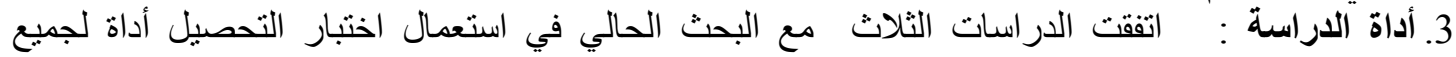

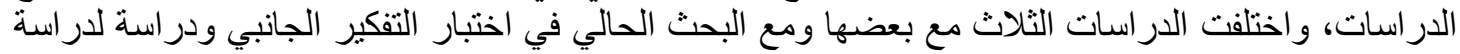
(حسن،مند2018) وفي مقياس الدافعية العقلية لدر اسة (جميل، 2018) ودر اسة (حميدي، 2014) في مقياس الاتجاه

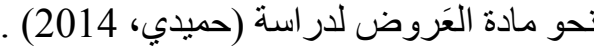

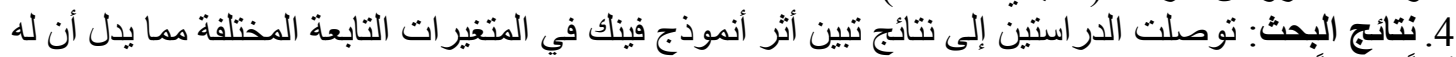

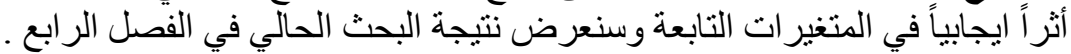




\section{الفصل الثالث \\ منهج البحث واجراءاته الته}

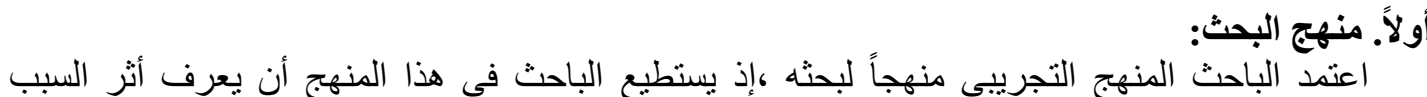

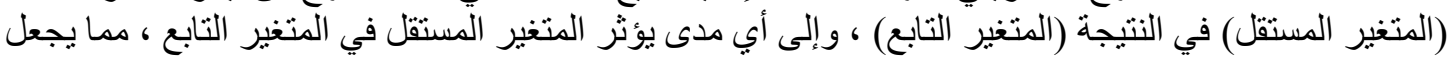

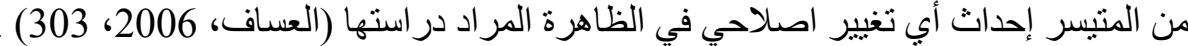

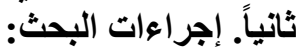

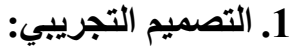

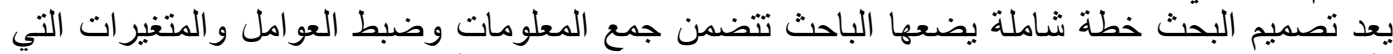

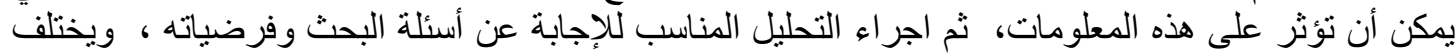

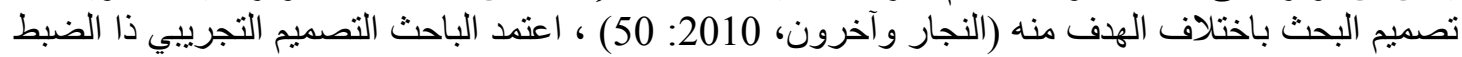

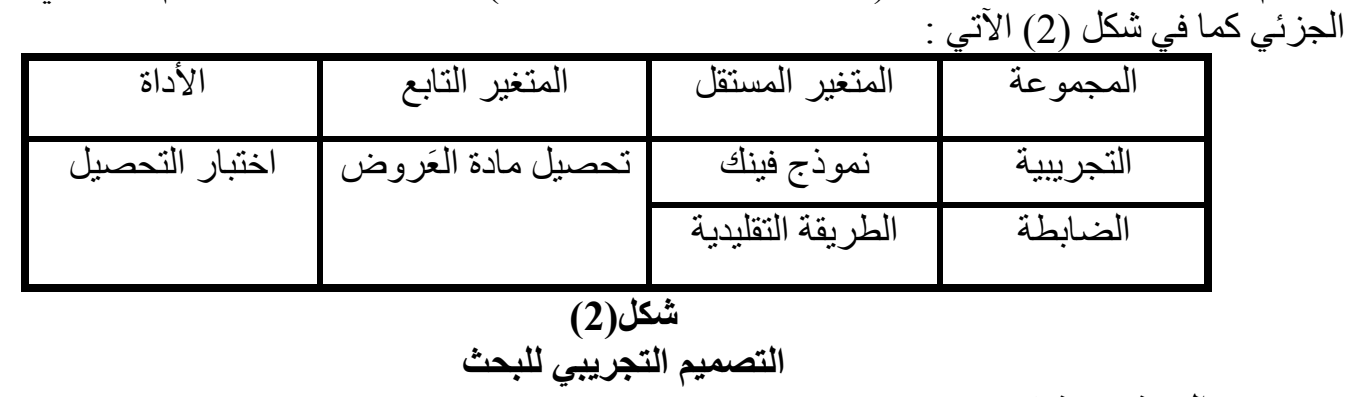

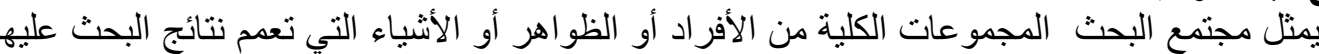

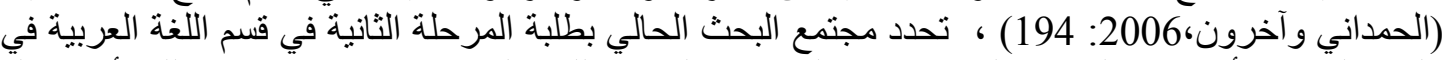

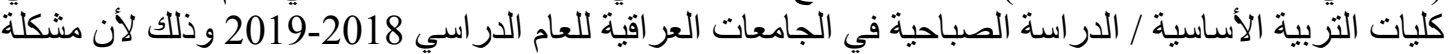

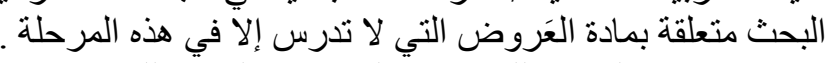

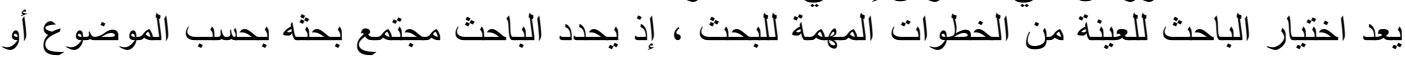

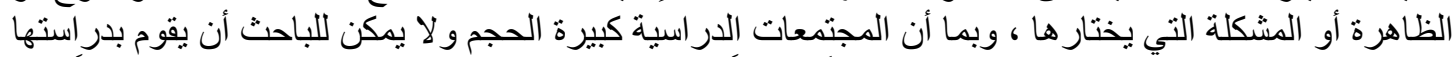

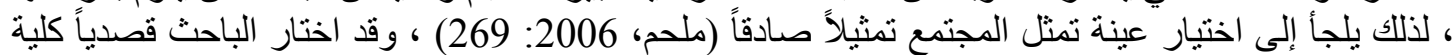

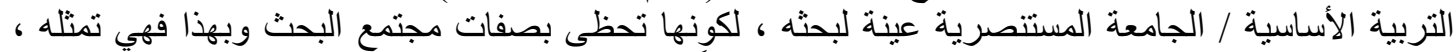

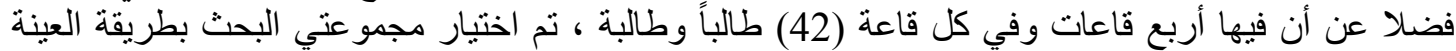

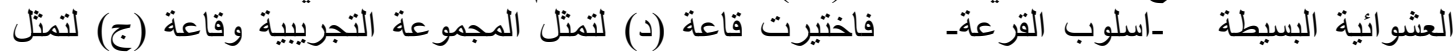

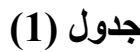

المجمو عة الضابطة جدول (2).

الاخيار العثوائي لعينة البحث و واعدادها

\begin{tabular}{|c|c|c|}
\hline عدد الطلبة & آلقاعة & المجمو عة \\
\hline 42 & د & التجريبية \\
\hline 42 & ج & الضابطة \\
\hline 84 & & المجموع \\
\hline
\end{tabular}

3. تكافؤ مجموعتى البحث :

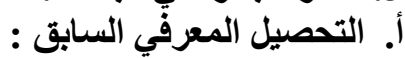

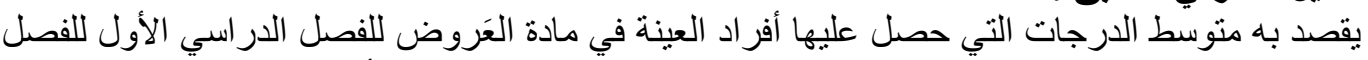

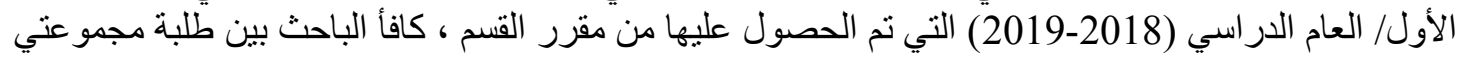




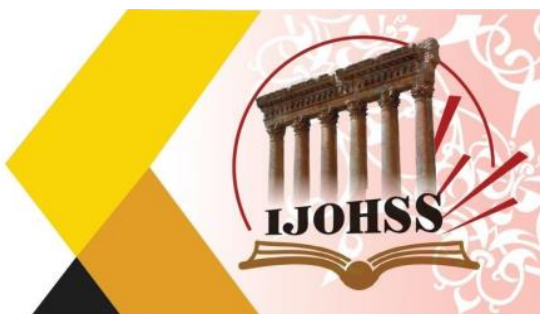

البحث في هذا المتغير ، إذ بلغ منوسط درجات المجموعة التجرييية (67,74) ومتوسط درجات المجموعة

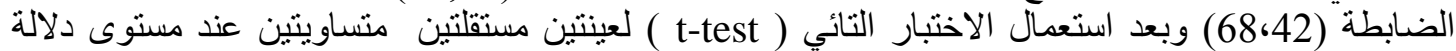

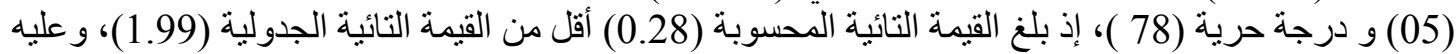

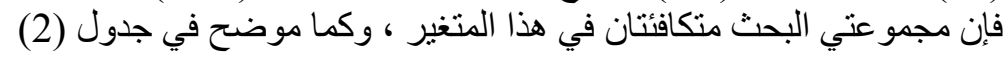

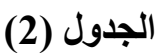

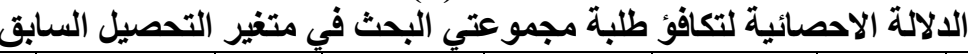

\begin{tabular}{|c|c|c|c|c|c|c|c|c|}
\hline \multirow{3}{*}{ 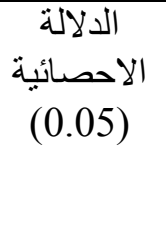 } & \multirow{2}{*}{\multicolumn{2}{|c|}{ التائية }} & \multirow{3}{*}{$\frac{3}{3}$} & \multirow[t]{3}{*}{ التباين } & \multirow{3}{*}{ المعياري } & \multirow{3}{*}{ الحسابي } & \multirow{3}{*}{ أفراد } & \multirow[t]{3}{*}{ المجموعة } \\
\hline & & & & & & & & \\
\hline & సै. & ? & & & & & & \\
\hline \multirow[t]{3}{*}{ غير دالة } & \multirow{3}{*}{ 亏. } & \multirow{3}{*}{$\begin{array}{l}\infty \\
\text { N. } \\
0 \\
2 \\
\infty \\
\text { n. } \\
0\end{array}$} & \multirow[t]{3}{*}{82} & 55,05 & 7,42 & 67,74 & 42 & التجريبية \\
\hline & & & & \multirow[t]{2}{*}{73,78} & & \multirow[t]{2}{*}{68,42} & 42 & الضابطة \\
\hline & & & & & & & 84 & المجموع \\
\hline
\end{tabular}

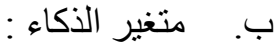
اعتمد الباحث اختبار أوتس (Otis) للقدرة العقلية ، وقد شمل الاختبار (50 فقرة) وفي ضو ألاء الإجابات تحدد

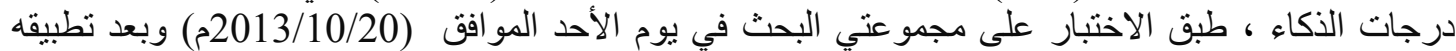

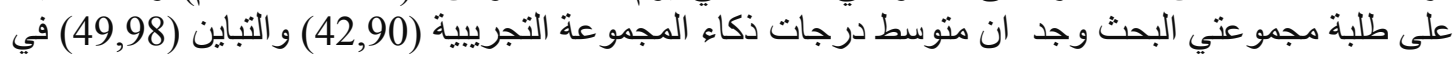

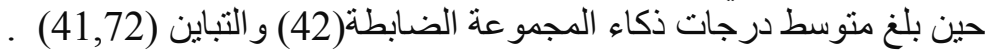

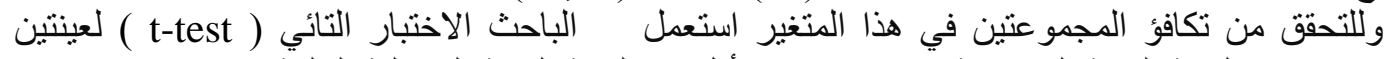

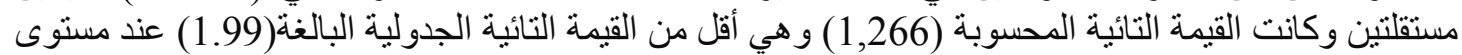
دلالة (0,05) ودرجة حرية (82) مما يدل على أن المجمو عتين التجرييية والضابطة متكافئتان في هذا المتغير

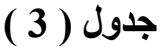

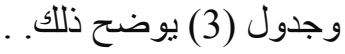

الدالة الاحصائية لتكافؤ طلبة مجموعتي البحث في متغير الأكاء

\begin{tabular}{|c|c|c|c|c|c|c|c|c|}
\hline \multirow{3}{*}{ الاحصائية } & \multirow{2}{*}{\multicolumn{2}{|c|}{ القائية }} & \multirow{3}{*}{$\frac{3}{3}$} & \multirow[t]{3}{*}{ التباين } & \multirow{3}{*}{ المعياري } & \multirow{3}{*}{ الحسابي } & \multirow{3}{*}{ ألعر اد } & \multirow[t]{3}{*}{ المجمو عة } \\
\hline & & & & & & & & \\
\hline & స̆. & $\begin{array}{l}\overline{3} \\
3 \\
3\end{array}$ & & & & & & \\
\hline \multirow[t]{3}{*}{ غير دالة } & \multirow{3}{*}{$\stackrel{\Omega}{\Omega}$} & \multirow{3}{*}{ 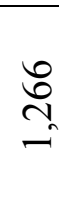 } & \multirow[t]{3}{*}{82} & 49,98 & 7,07 & 42,90 & 42 & التجريبية \\
\hline & & & & \multirow[t]{2}{*}{41,73} & \multirow[t]{2}{*}{6,46} & \multirow[t]{2}{*}{42} & 42 & الضابطة \\
\hline & & & & & & & 84 & المجموع \\
\hline
\end{tabular}

4. ضبط المتغيرات الاخيلة (غير التجريبية ): أ. الحو ادث المصاحبة : لم يصحب التجربة أبي حادث من شأنه أن يؤثر في ظروف التجربة طول مدة اجر ائها . 


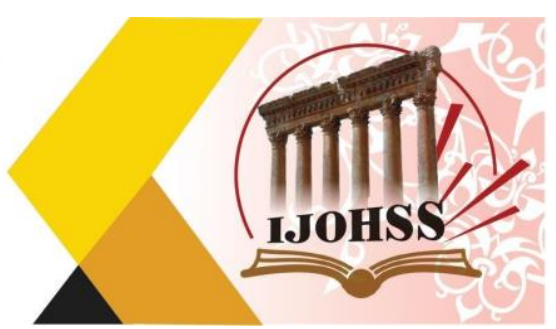

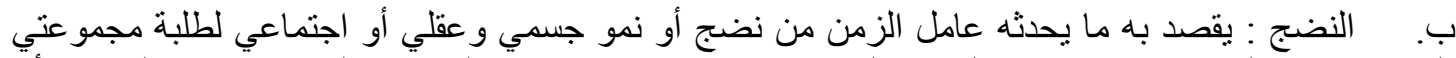

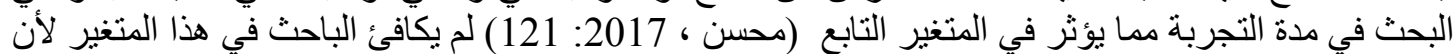

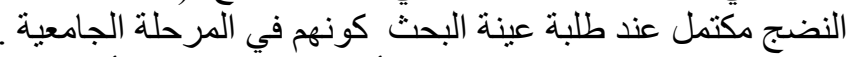

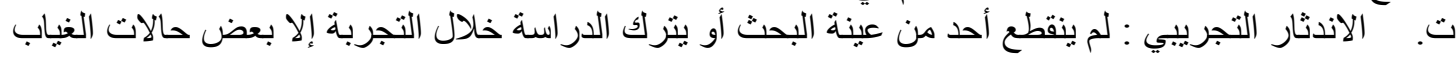

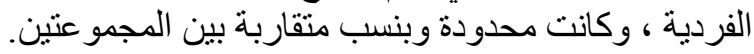

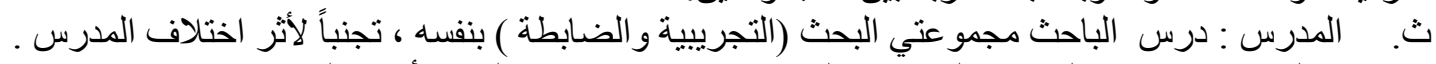

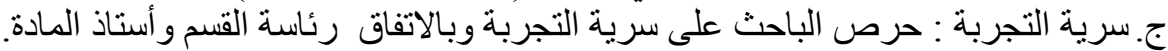

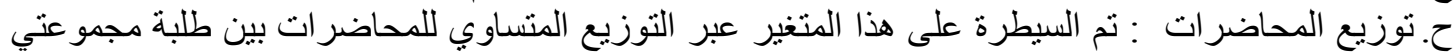

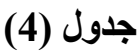
البحث وكما موضح في جدول (4) الآتي :

جلول توزيع محاضرات العَروض بين مجموعتي البحث

\begin{tabular}{|c|c|c|}
\hline المحاضرة الثانية & المحاضرة الأولى & اليوم اليوم \\
\hline المجوعة الضابطة & المجمو عة التجريبية & الثلاثاء \\
\hline المجمو عة التجريبية & المجمو عة الضابطة & الأربعاء \\
\hline
\end{tabular}

خ. مدة التجربة : كانت مدة التجربة موحدة ومتساوية ، إذ بدأت يوم الثثلاثاء المو افق 2019/3/5، و انتهت يوم 2019/4/30

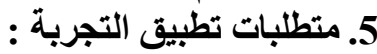

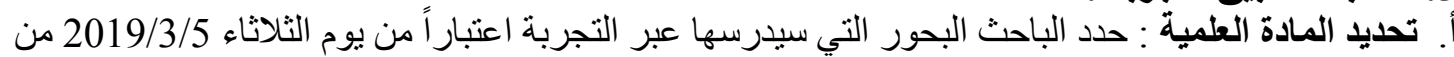

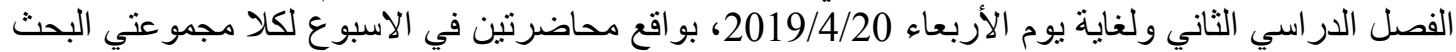

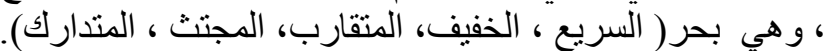
ب. بي صياغة الأهداف السلوكية : هي أهداف إجرائية قابلة للملاحظة والقياس القياس ، تشتق من الأهداف الفرعية

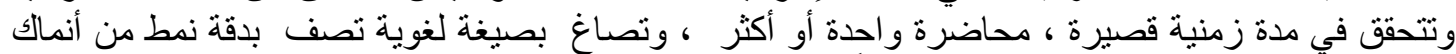

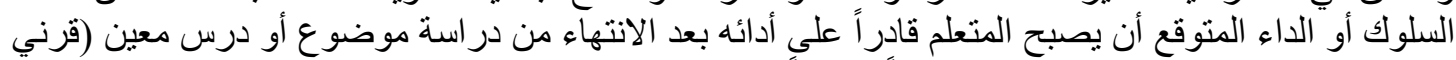

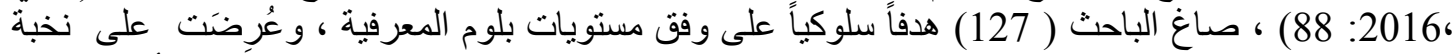

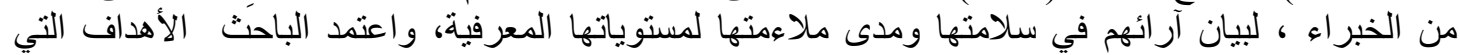

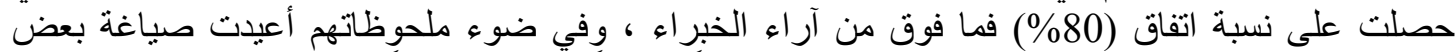

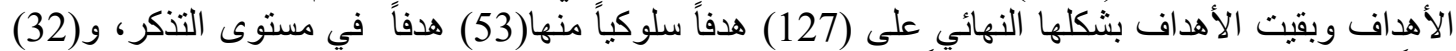

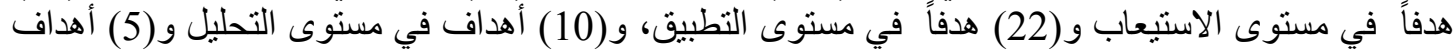

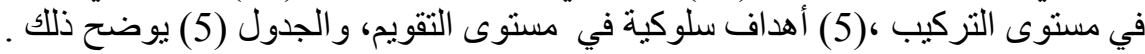

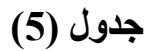

توزيع الأهداف السلوكية بحسب مستويات بلوم المعرفية

\begin{tabular}{|c|c|c|c|c|c|c|c|c|}
\hline \multirow{2}{*}{ 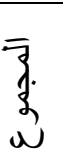 } & \multicolumn{6}{|c|}{ مستوى الأهداف } & \multirow[t]{2}{*}{ محتوى بحر } & \multirow[t]{2}{*}{$ت$} \\
\hline & التقويم & التركيب & التحليل & التطبيث & الفهم & التنكر & & \\
\hline 23 & 1 & 1 & 2 & 4 & 5 & 10 & المتقارب & 1 \\
\hline 20 & 1 & 1 & 2 & 4 & 5 & 7 & المجتث & 2 \\
\hline 26 & 1 & 1 & 2 & 4 & 7 & 11 & الخفيف & 3 \\
\hline 28 & 1 & 1 & 2 & 6 & 7 & 11 & 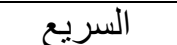 & 4 \\
\hline
\end{tabular}




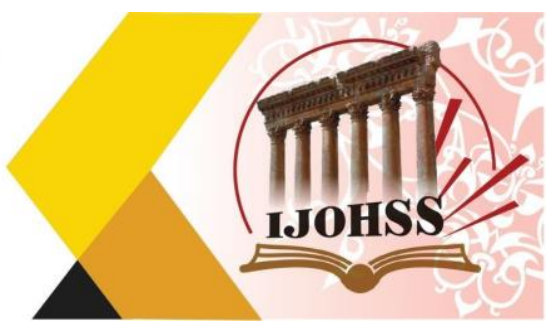

\begin{tabular}{|c|c|c|c|c|c|c|c|c|}
\hline 30 & 1 & 1 & 2 & 4 & 8 & 14 & 5 \\
\hline 127 & 5 & 5 & 10 & 22 & 32 & 53 & \multicolumn{2}{|l|}{ المتدمورك } \\
\hline
\end{tabular}

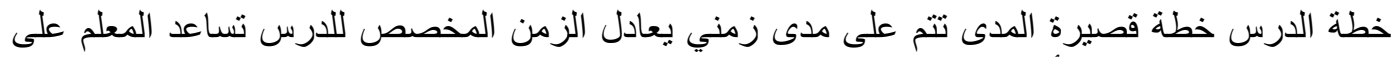

رسم صورة واضحة لما يمكن أن يقوم به هو الهد وطلابه خلال الدرس (الطناوي، 2008:

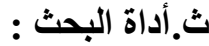

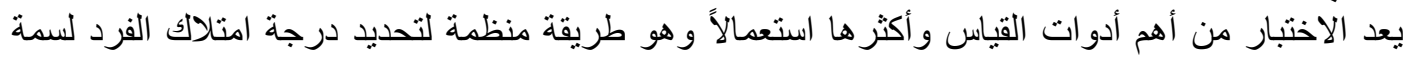

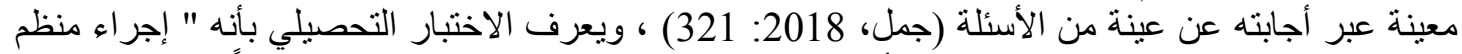

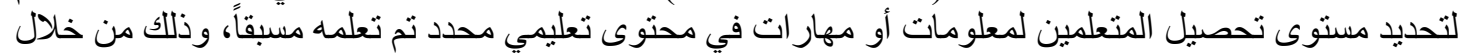

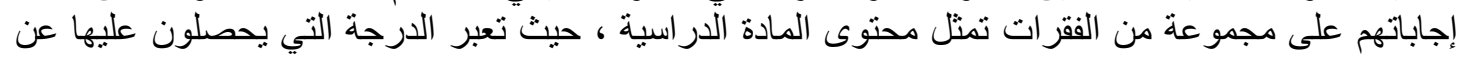

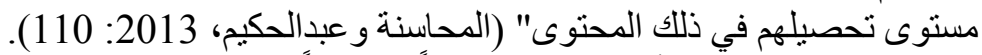

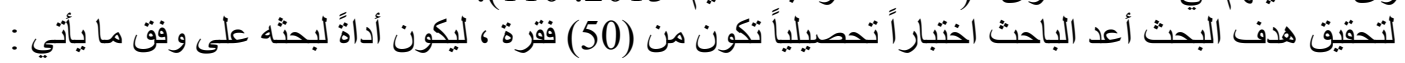

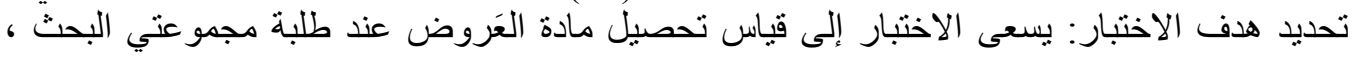

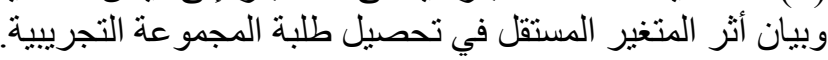

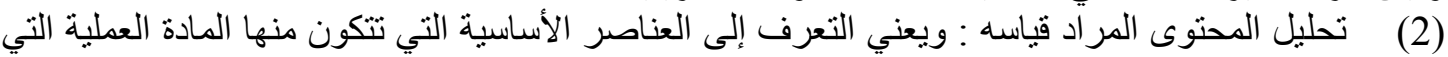

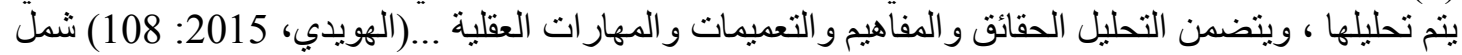
المحتوى المر اد قياسه (5) بحور من موضوعات العَروض النقات المقررة للفصل الدراسي الثاني في كليات التربية (3) إعداد جدول المواصفات : هو عبارة عن جدول تكراري مزدوج تمثل أعمدته الأهداف ، وتمثل أسطره

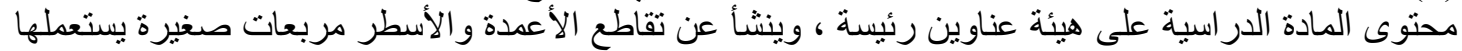

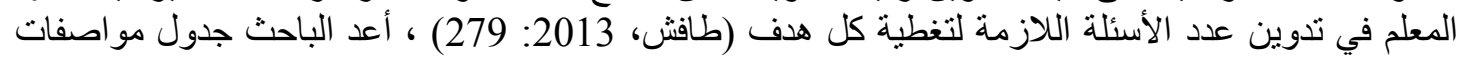

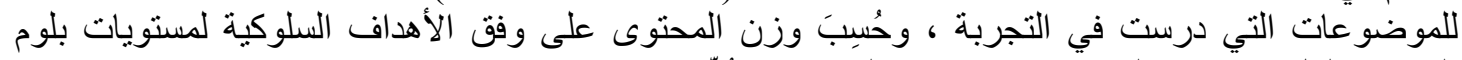

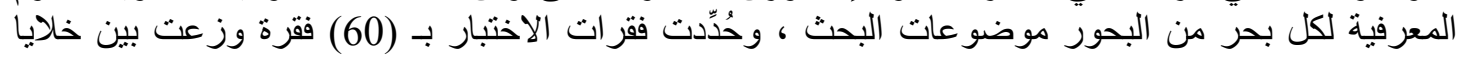
جدول المو اصفات وكما في جدول (6) الآتي :

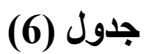

جلول المواصفات لاختبار التحصيل (6)

\begin{tabular}{|c|c|c|c|c|c|c|c|c|}
\hline \multirow{3}{*}{$\begin{array}{l}\overline{3} \\
\dot{\alpha} \\
\omega\end{array}$} & \multicolumn{6}{|c|}{ وزن مستويات الأهداف السلوكية } & \multirow{3}{*}{ المحتوى } & \multirow{3}{*}{ الموضوع } \\
\hline & تقوي & تركيب & تحليل & تطبيق & فهم & تذكر & & \\
\hline & 0,04 & 0,04 & 0,07 & 0.17 & 0,26 & 0,42 & & \\
\hline 11 & 1 & 1 & 1 & 2 & 2 & 4 & $\% 18,11$ & المتقارب \\
\hline 10 & 1 & 1 & 1 & 2 & 2 & 3 & $\% 15,75$ & المجتث \\
\hline 13 & 1 & 1 & 1 & 2 & 3 & 5 & $\% 20,47$ & الخفيف \\
\hline 13 & 1 & 1 & 1 & 2 & 3 & 5 & $\% 22,05$ & السريع \\
\hline 13 & 1 & 1 & 1 & 2 & 3 & 5 & $\% 23,62$ & المتدارك \\
\hline 60 & 5 & 5 & 5 & 10 & 13 & 22 & $\% 100$ & المجموع \\
\hline
\end{tabular}

(4) صياغة فقرات الاختبار: صاغ الباحث سؤ الين : الأول من (35) فقرة من نوع الاختيار من متعدد ،

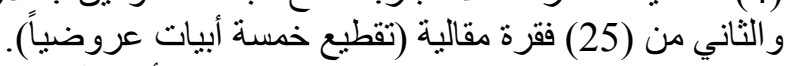

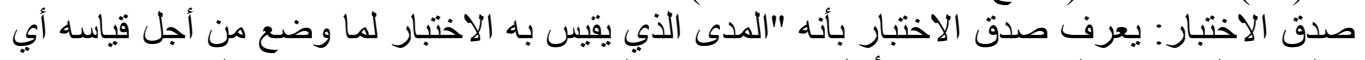

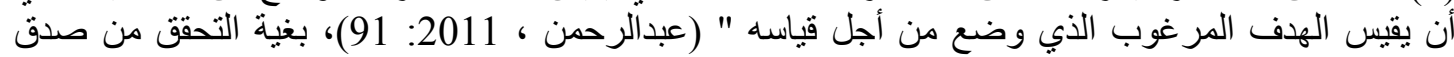

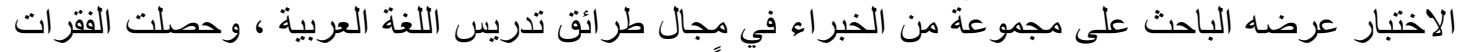
جميعها على نسبة اتفاق (0,90) وبهذا يعد الاختبار صنادقاً. 


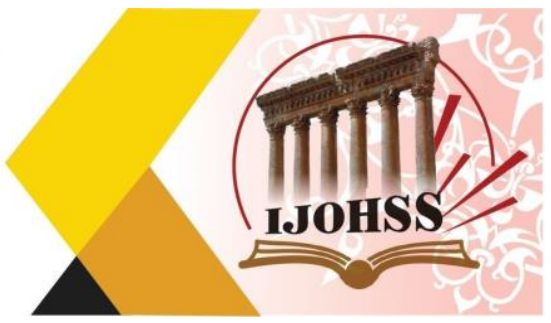

التجربة الاسنطلاعية : لمعرفة الوقت الازم للاختبار وصدقه البنائي وثباته أجرى الباحث اختبار العينة

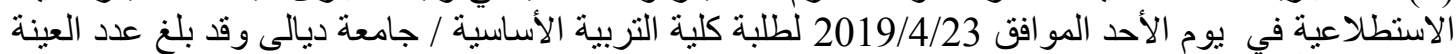

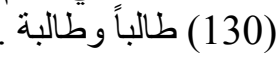
- حسب معدل الوقت المستغرق للإجابة عن فقرات الاختبار بحساب الزمن الذي أستغرقه الطلبة جميعهم (9750)

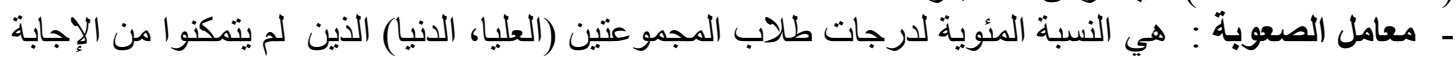

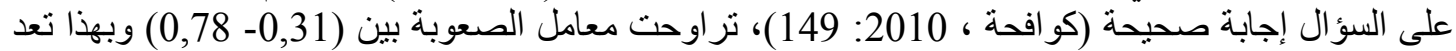
مقبولة . ـ معامل تمييز الفقرات : يقصد به قدرة الفقرة على تمييز الفروق الفردية بين الطلاب وقدرتها على التمييز بين

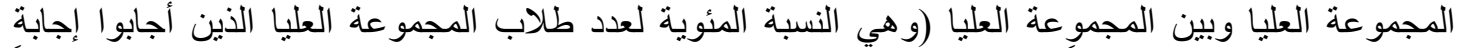

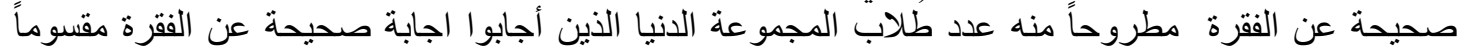

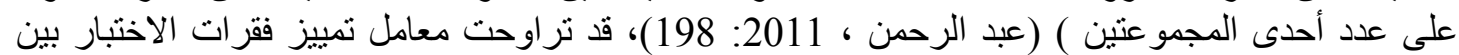

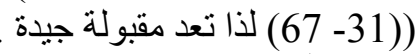

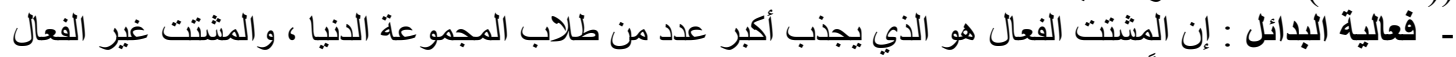

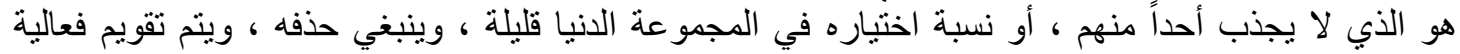

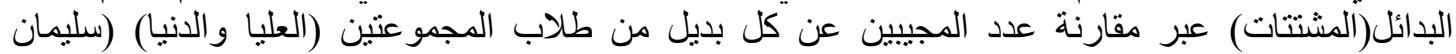

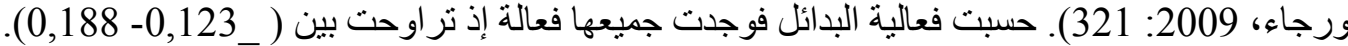

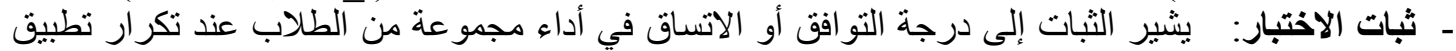

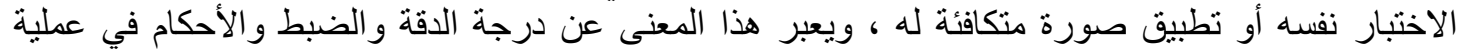

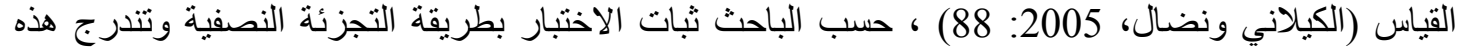

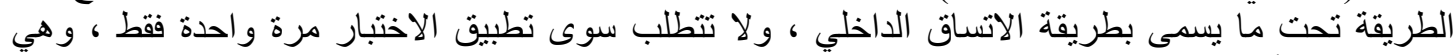

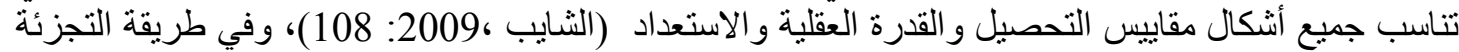

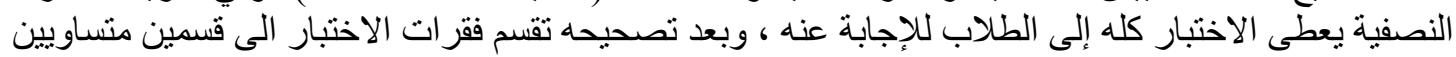

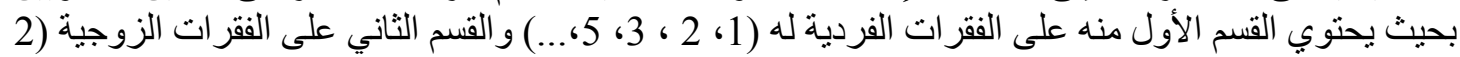

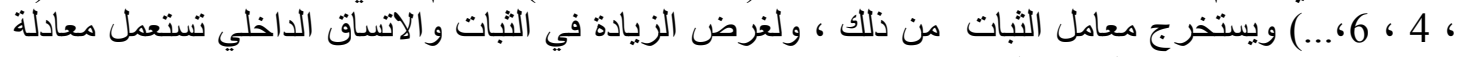

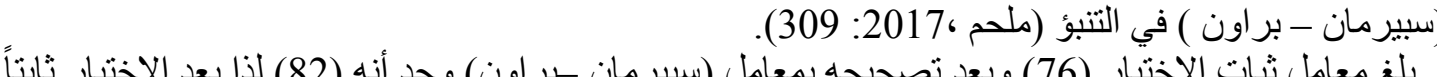

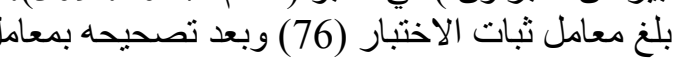

اتبع الباحث في أثناء تطبيق التجربة الاجر اءات الآتية : ـ تتفيذ التجربة : عند استكمال الباحث منطلبات اجر اء التجربة وتية التحقيق التكافؤ وتحديد المفردات الدراسية لمادة

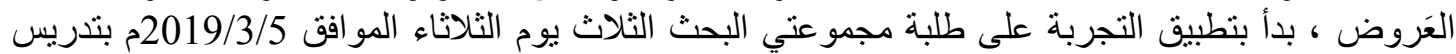

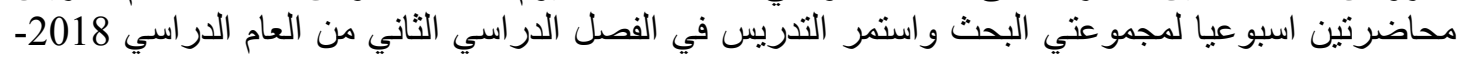

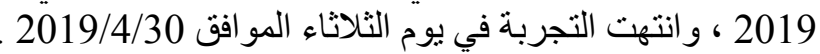

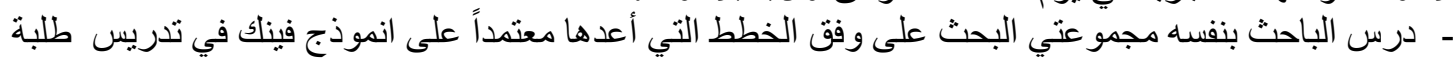

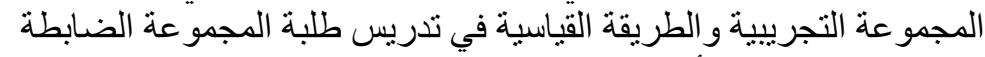

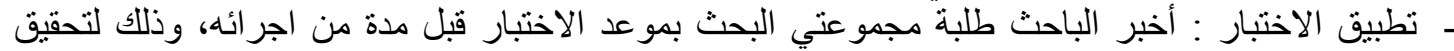

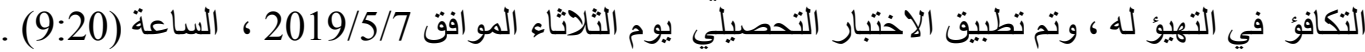
الوسائل الاحصائية : الأله

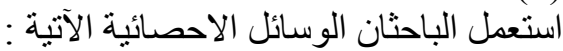

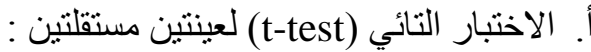
استعمل لاختبار دلالة الفروف بين مجموعتي البحث في التكافؤ الاحصائي في متغير التحصيل المعرفي السابق ومتغير الذكاء ، وفي تحليل نتائج اختبار التحصيل. 


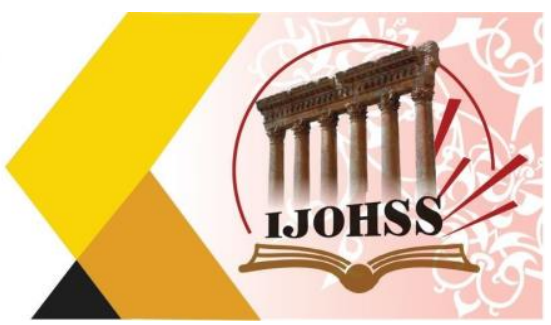

ب. معامل الصعوبة ومعامل التمبيز ومعادلة فعالية البدائل وبييرسون وسبيرمان براون.

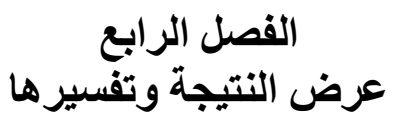

\section{يعرض الباحث في هذا الفصل النتيجة التي توصل اليها على وفق هدف البحث ، ثم يفسرها :} أولاً. عرض النتيجة : البعز

للتحقق من الفرضية الصفرية التي تنص على : ( لا يوجد فرق ذو دلالة إحصائية عند مستوى الدلالة (0,05)

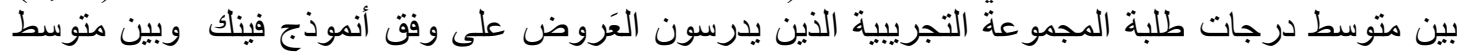

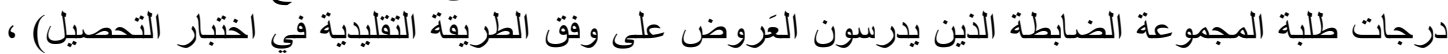

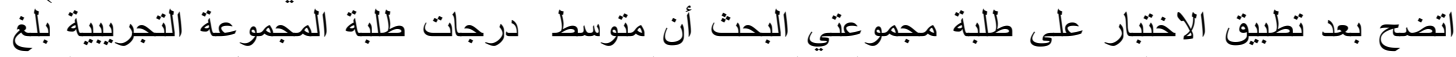

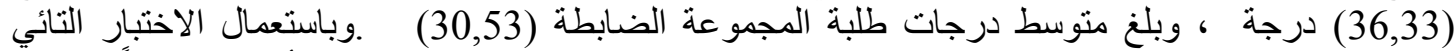

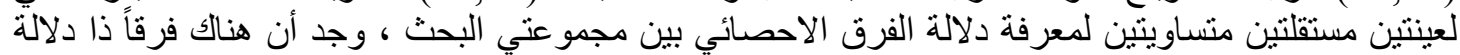

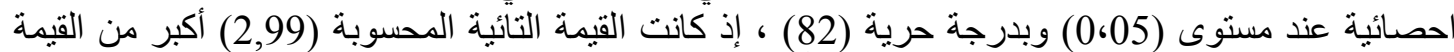

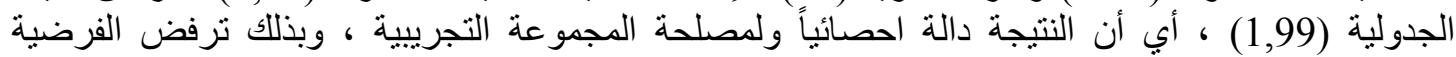

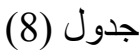

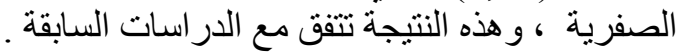

الدلالة الاحصائية لمجموعتي البحث في اختبار التحصيل

\begin{tabular}{|c|c|c|c|c|c|c|c|c|}
\hline \multirow{2}{*}{ الإحصنائية } & \multicolumn{2}{|c|}{ القيمة التائية } & \multirow[b]{2}{*}{$\frac{3}{3}$} & \multirow[b]{2}{*}{ 司. } & \multirow[b]{2}{*}{$\overline{\bar{y}} \bar{y}$} & \multirow{2}{*}{ الحسنوسي } & \multirow[t]{2}{*}{ العدد } & \multirow[t]{2}{*}{ المجمو عة } \\
\hline & $\begin{array}{l}\overline{7} . \\
\bar{y} \cdot \bar{\gamma}\end{array}$ & $\begin{array}{l}\overline{3} \\
3 \\
\frac{3}{3}\end{array}$ & & & & & & \\
\hline \multirow[t]{2}{*}{ دال إحصائيا } & \multirow{2}{*}{ बे } & \multirow{2}{*}{8} & \multirow[t]{2}{*}{82} & $58 \cdot 98$ & 7,68 & 36,33 & 33 & التجريبية \\
\hline & & & & 95,06 & 9,75 & 30.53 & 30 & الضـابطة \\
\hline
\end{tabular}

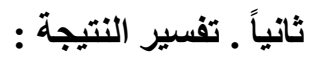

يمكن تفسير تفوق طلبة المجمو عة التجرييية على طلبة المجمو عة الضابطة إلى الأسباب الآتية:

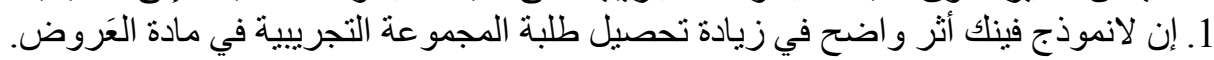

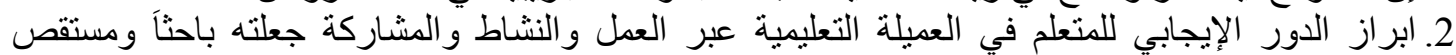
لمعرفة العلمية. 3. توفير المعلم لأنشطة التعلم التي يكون فيها مو اقف ثم ربطها بالمعرفة السابقة عند المتعلم جعلت عملية التعلم

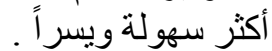

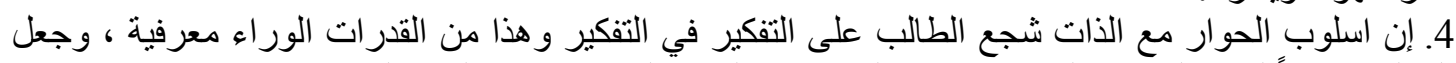

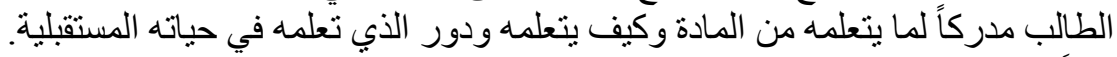

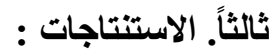

1. ز اد التدريس على وفق النموذج فينك مستوى تحصيل الطلبة عبر مشاركتهم الايجابية في العملية التعليمية .

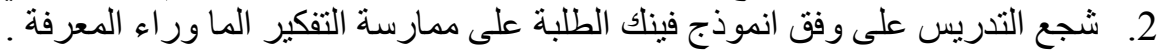

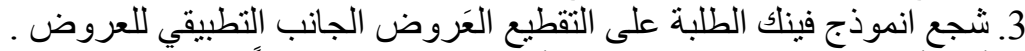

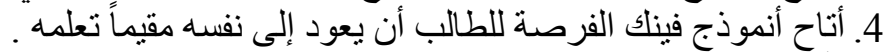

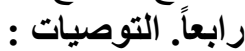
1. ابعرورة الإفورة من انموذج فينك في تدريس العَروض. 


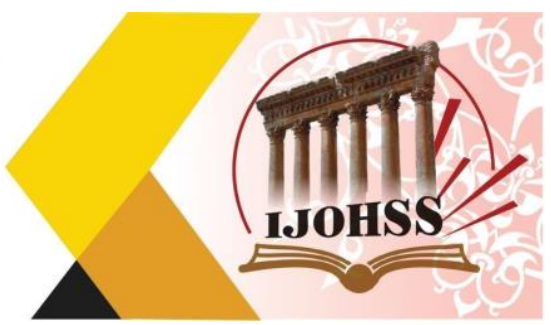

$$
\text { 2. إتاحة الفرصة للطلبة أن يمارسو الحوار الحمار مع الذات ومع الآخرين وتقويم تعلمهم . }
$$

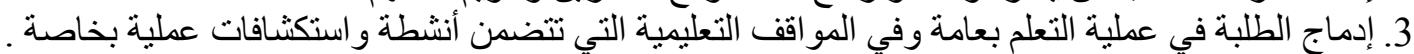
4. تثجيع الطلبة على تدوين ملحوظاتهم حول المادة التي تعلمو هاً من أجل ربط المعلية المعرفة السابقة بمو اقف التعلم .

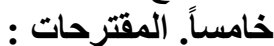

استكمالا للبحث الحالي يقترح الباحث اجر اء دراسات ممانلة تهدف إلى :

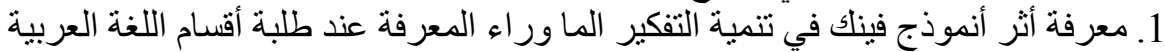
2. معرفة أثر أنموذج فينانك في تحصيل في فردية فروع اللغة العربية الأخرى . 3. معرفة أنموذج فينك في تتمية المهار فيك الدلالية عند طلبة قسم اللعة العربية في مادة البلاغة .

(المصادر

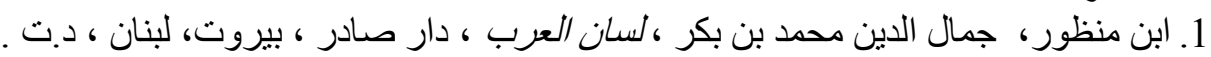

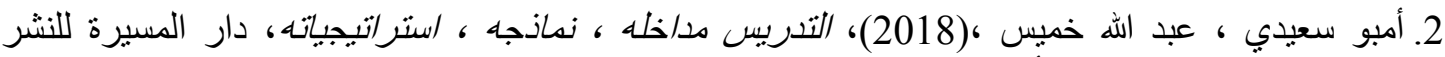

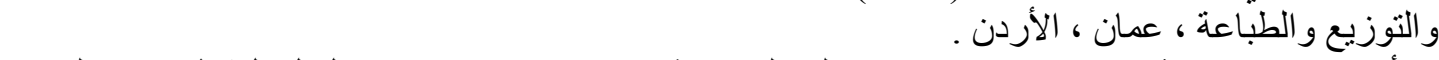

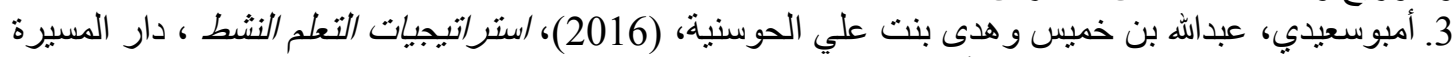
للنشر و التوزيع و الطباعة ، عمان ، الأردن.

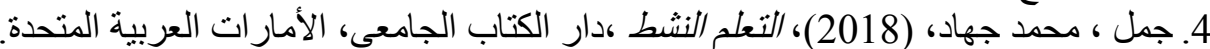

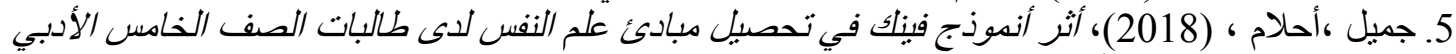

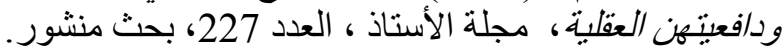

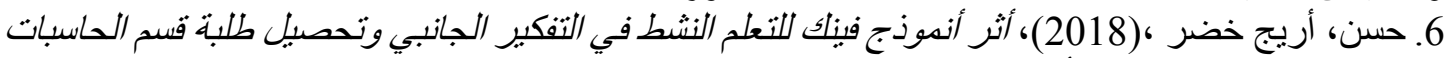

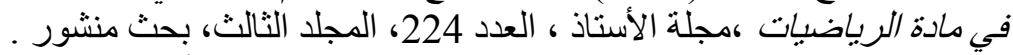

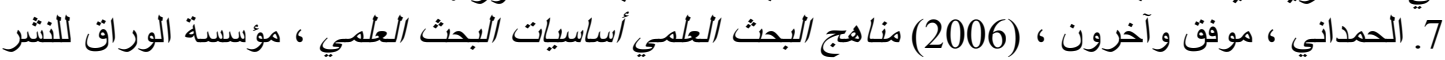

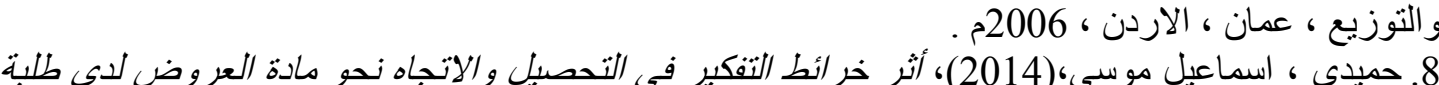

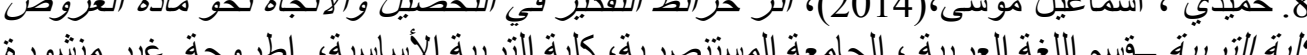

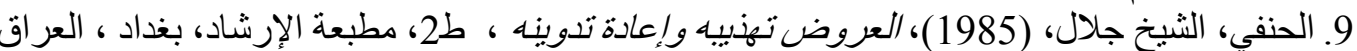

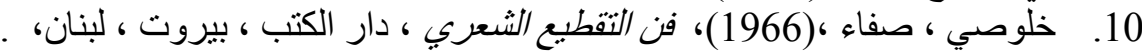

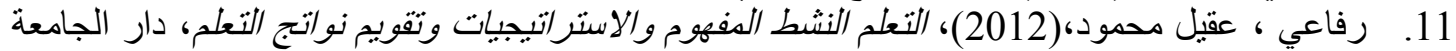

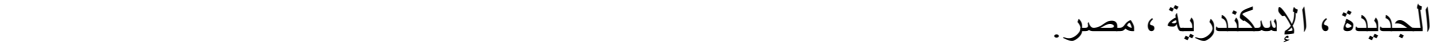

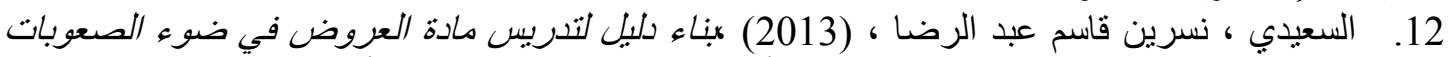

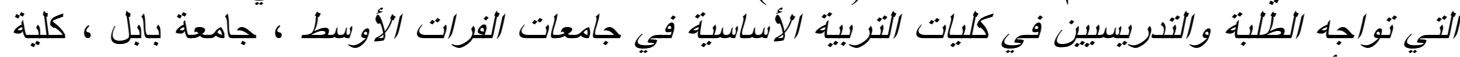
التربية الأساسية .رسالة ماجستير غيلنير في منشورة. 13. سليمان ، أمين علي محمد ورجاء محمود أبو علام ، (2010)، القباس والثقويم في العلوم الانسانية ، دار

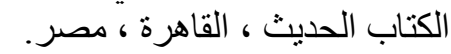

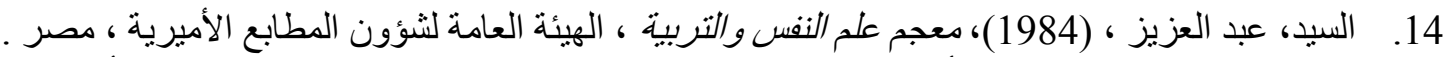

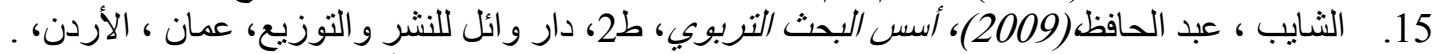

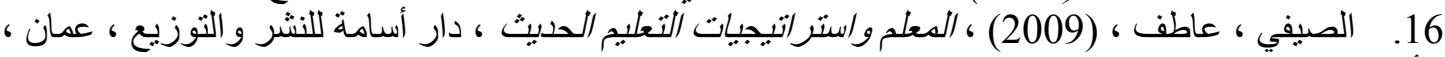

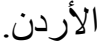

17. طافش ، محمود، (2013)، كبف تكون معلدًا مبدعًا، جعينة للنشر و التوزيع ، عمان ، الأردن .

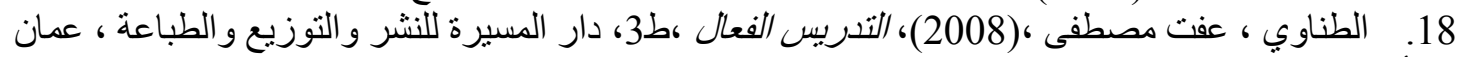
، 19.

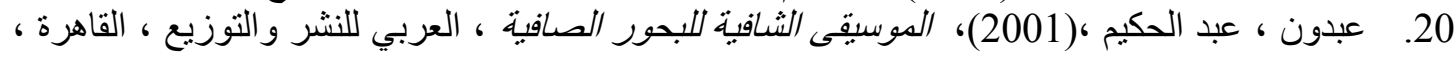




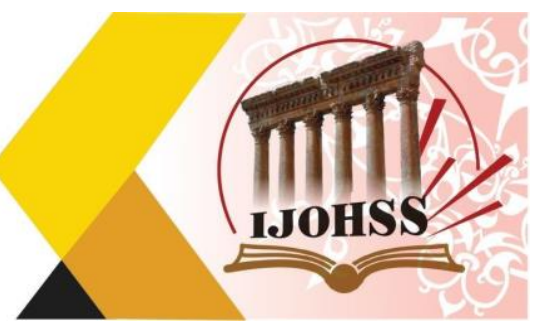

21. العساف ، صالح محمد،02006)، الدذخل إلى البحث في العلوم السلوكية ، مكتبة العبيكان ، الرياض ، السعودية.

22. عطية ، محسن علي ،(2018)، التعلم النشط /ستر/تيجيات وأساليب حديثة ، دار الثروق ، عمان ،

23 الاردن. فضل ، عاطف، (2015)، العروض التطبقي، ، دار المناهج للنشر و التوزبع، عمان ، الأردن.

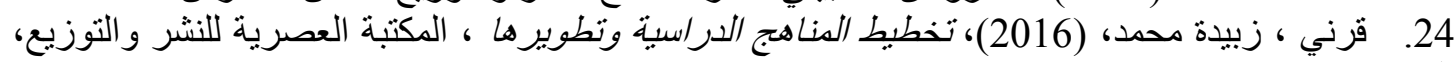

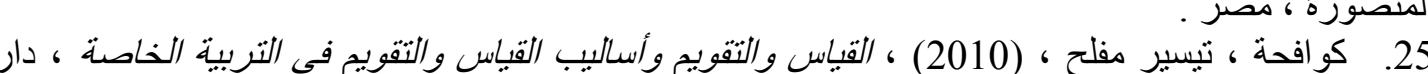

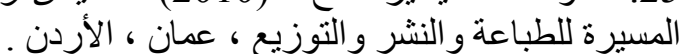

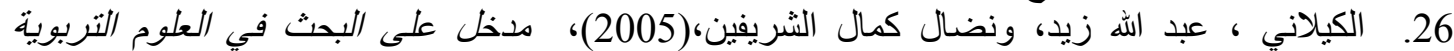

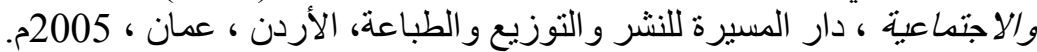

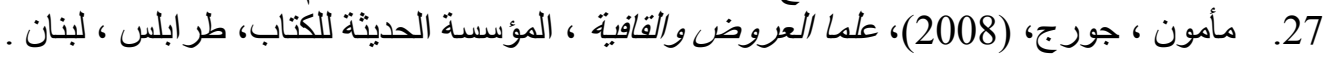

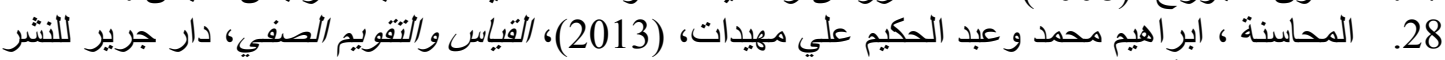

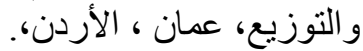

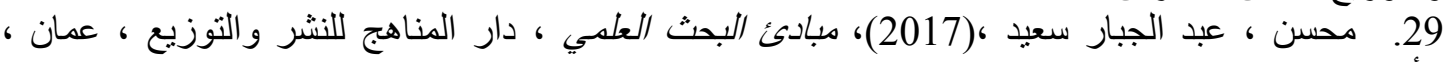
الاردن . مصطفى ، محمود ، (1996)، أهدى سبيل إلى علمى الخليل العروض والقافية ، عالم الكتب ، بيروت ، بنان . والطباعة ، عمان ، الأردن.

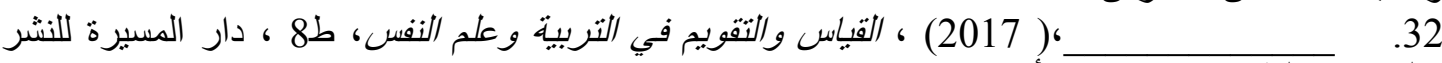
و التوزيع و الطباعة ، عمان ، الأردن.

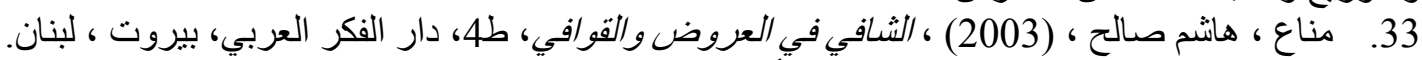

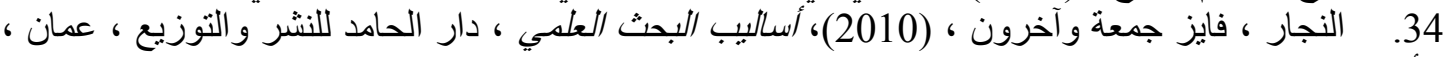
(الأردن.

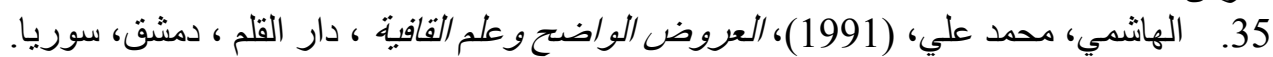

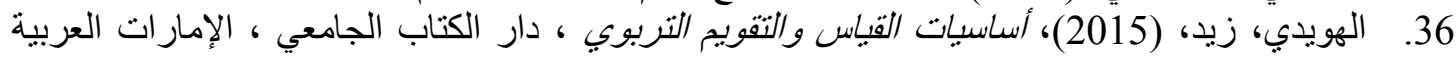

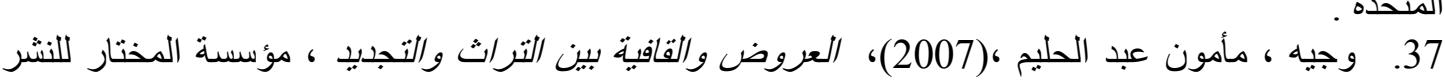

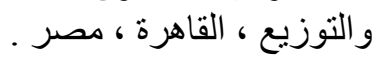

\section{References}

1. Ibn Manzur, Jamal al-Din Muhammad bin Bakr, Lisan al-Arab, Dar Sader, Beirut, Lebanon, dt.

2. Ambo Saeedi, Abdullah Khamis, (2018), the teaching, its entries, its models, its strategies, Dar Al-Masirah for Publishing, Distribution and Printing, Amman, Jordan. 3. Ambosaidi, Abdullah Bin Khamis and Hoda Bint Ali Al Hosania, (2016), Strategies for Active Learning, Dar Al Masirah for Publishing, Distribution and Printing, Amman, Jordan.

4. Jamal, Muhammad Jihad, (2018), Active Learning, University Book House, United Arab Emirates. 


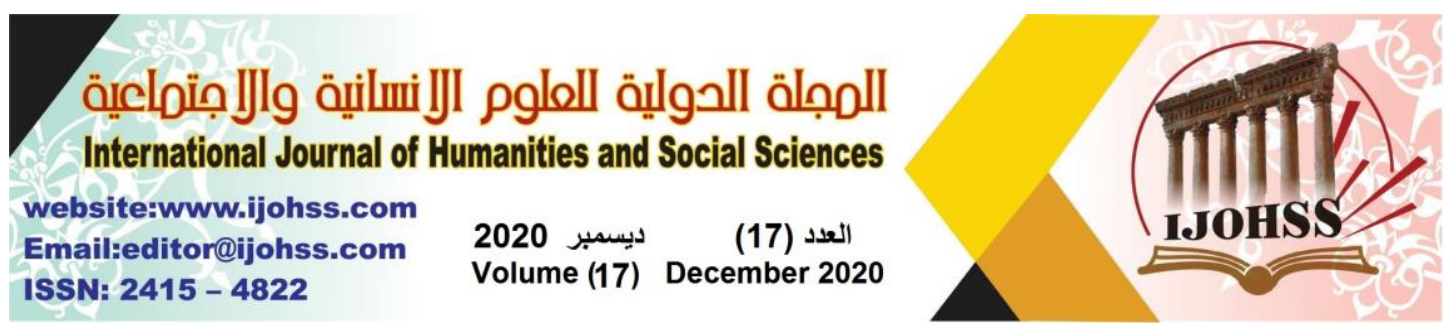

5. Jamil, Ahlam, (2018), The Effect of Fink Model on the Achievement of Psychology Principles of Fifth-Grade Literary Students and Their Mental Motivation, Al-Ustad Magazine, Issue No. 227, published research

6. Hassan, Areej Khader, (2018), The Effect of Fink Model for Active Learning on Lateral Thinking and Students' Achievement in the Department of Computers in Mathematics, Al-Ustad Magazine, Issue 224, Volume Three, Published Research

7. Al-Hamdani, Mwafak and others, (2006) Scientific Research Methods, Fundamentals of Scientific Research, Al-Warraq Foundation for Publishing and Distribution, Amman, Jordan, 2006.

8. Hamidi, Ismail Musa, (2014), The Impact of Thinking Maps on Achievement and the Trend Toward Presentation Subject for Students of the College of Education Department of Arabic Language, Al-Mustansiriya University, College of Basic Education. Unpublished thesis

9. Al-Hanafi, Sheikh Jalal, (1985), Presentations Refining and Recording it, 2nd Edition, Al-Irshad Press, Baghdad, Iraq.

10. Khulousi, Safa, (1966), The Art of Poetic Cut, Dar Al Kutub, Beirut, Lebanon

10. Khulousi, Safa, (1966), The Art of Poetic Cut, Dar Al Kutub, Beirut, Lebanon.

11. Rifai, Aqeel Mahmoud, (2012), Active Learning the Concept, Strategies and Evaluation of Learning Outcomes, New University House, Alexandria, Egypt.

12. Al-Saidi, Nasreen Qasim Abd al-Reda, (2013), Building a guide for teaching the subject of presentations in light of the difficulties faced by students and teaching staff in the Faculties of Basic Education in the Universities of the Middle Euphrates, University of Babylon, College of Basic Education. Unpublished MA thesis.

13. Soliman, Amin Ali Muhammad and Raja Mahmoud Abu Allam, (2010), Measurement and Evaluation in the Humanities, Dar Al-Kitab Al-Hadith, Cairo, Egypt.

14. Al-Sayed, Abdel-Aziz, (1984), Dictionary of Psychology and Education, General Authority for Emiri Press Affairs, Egypt

15. Al-Shayeb, Abdel-Hafez, (2009), Foundations of Educational Research, 2nd Edition, Wael House for Publishing and Distribution, Amman, Jordan.

16. Al Saifi, Atef, (2009), The Teacher and Strategies of Modern Education, Osama House for Publishing and Distribution, Amman, Jordan.

17. Tafesh, Mahmoud, (2013), How to be a Creative Teacher, Juhayna Publishing and Distribution, Amman, Jordan.

18. Al-Tanawi, Effat Mustafa, (2008), Effective Teaching, 3rd Edition, Dar AlMasirah for Publishing, Distribution and Printing, Amman, Jordan.

19. Abdul-Rahman, Ahmad Muhammad, (2011), Exam Design, Osama House for Publishing and Distribution, Amman, Jordan.

20. Abdoun, Abdel Hakim, (2001), The Healing Music of the Pure Sea, Al-Arabi for Publishing and Distribution, Cairo, Egypt.

21. Al-Assaf, Salih Muhammad, 02006), Introduction to Research in the Behavioral Sciences, Al-Obeikan Library, Riyadh, Saudi Arabia. 


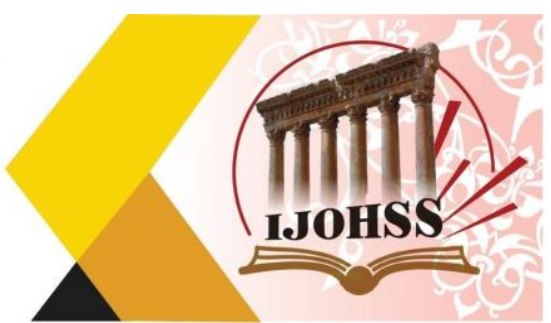

22. Attia, Mohsen Ali, (2018), Active Learning, Modern Strategies and Methods, Dar Al-Shorouk, Amman, Jordan.

23. Fadl, Atef, (2015), Demographic Presentations, House of Approaches for Publishing and Distribution, Amman, Jordan.

24. Qarni, Zubaida Muhammad, (2016), Curriculum Planning and Development, Modern Library for Publishing and Distribution, Mansoura, Egypt.

25. Kawagha, Tayseer Mufleh, (2010), Measurement, Evaluation, and Methods of Measurement and Evaluation in Special Education, Dar Al-Masirah for Printing, Publishing and Distribution, Amman, Jordan.

26. Al-Kilani, Abdullah Zaid, and Nidal Kamal Al-Sharifain, (2005), Introduction to Research in Educational and Social Sciences, Dar Al-Masirah for Publishing, Distribution and Printing, Jordan, Amman, 2005 AD.

27. Mamoun, George, (2008), Science of performances and rhyme, Modern Book Foundation, Tripoli, Lebanon.

28. Al-Mahasna, Ibrahim Muhammad and Abdul Hakim Ali Muhaidat, (2013), Classroom Measurement and Evaluation, Jarir Publishing and Distribution House, Amman, Jordan.

29. Mohsen, Abdul-Jabbar Saeed, (2017), Principles of Scientific Research, House of Approaches for Publishing and Distribution, Amman, Jordan.

30. Mustafa, Mahmoud, (1996), A Path to My Knowledge, Hebron, Performances and Rhyme, World of Books, Beirut, Lebanon.

31. Melhem, Samehi Muhammad, (2006), Research Methods in Education and Psychology, 6th Edition, Dar Al-Masirah for Publishing, Distribution and Printing, Amman, Jordan.

32. (2017), Measurement and Evaluation in Education and Psychology, 8th Edition, Dar Al-Masirah for Publishing, Distribution and Printing, Amman, Jordan.

33. Manna'a, Hashem Salih, (2003), Al Shafi in Performances and Rhymes, 4th Edition, House of Arab Thought, Beirut, Lebanon.

34. Al-Najjar, Fayez Jumaa and others, (2010), Methods of Scientific Research, AlHamid House for Publishing and Distribution, Amman, Jordan.

35. Al-Hashemi, Muhammad Ali, (1991), Clear Performances and Rhyme Science, Dar Al-Qalam, Damascus, Syria.

36. Al-Huwaidi, Zaid, (2015), Fundamentals of Educational Measurement and Evaluation, University Book House, United Arab Emirates.

37. Wajih, Mamoun Abdel Halim, (2007), Performances and Rhymes between Heritage and Renewal, Al-Mukhtar Foundation for Publishing and Distribution, Cairo, Egypt. 


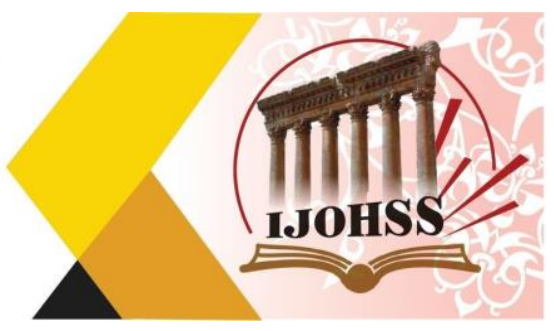

\section{الملحق}

\section{خطة نموذجية لتدريس مادة العروض على وفق انموذج فينك}

المرحلة : الثانية (د)

الوقت : 50 دقيقة 


$$
\begin{aligned}
& \text { - ما هي تفعيلات البيت ؟ }
\end{aligned}
$$

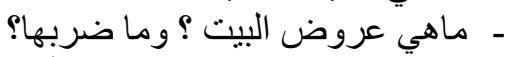

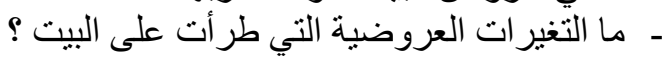

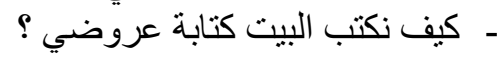

$$
\begin{aligned}
& \text { - ما هو البحر الذي ينتمي إليه البيت ؟ }
\end{aligned}
$$

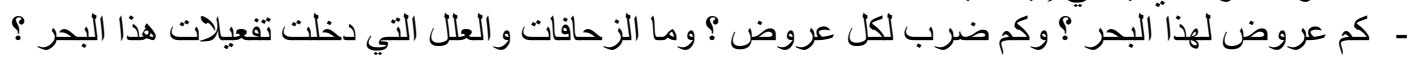

$$
\text { وما حكمها ؟ كروص }
$$

• التنفيذ العملي : تنفيذ الاستكثاف :

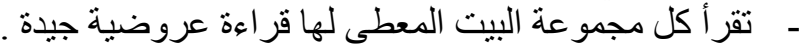

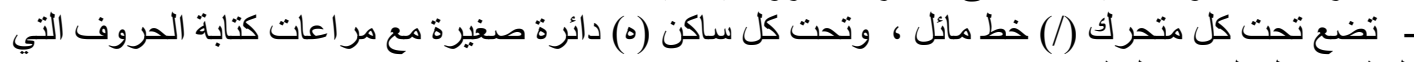

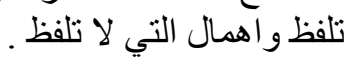

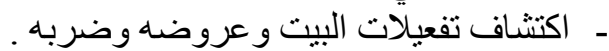

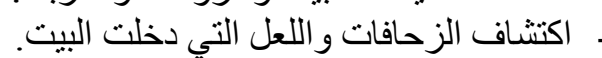
-

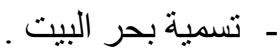

• الملاحظة : يقوم كل طالب بتسجيل ملحوظاته التي شاهدها في أثناء تنفيذه للاستكثاف. • الحوار مع الذات : يسجل كل طالب في دفتر المذكرات العلمية إجابته عن الأسئلة الآتية :

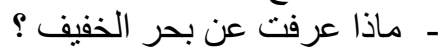

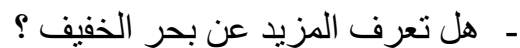

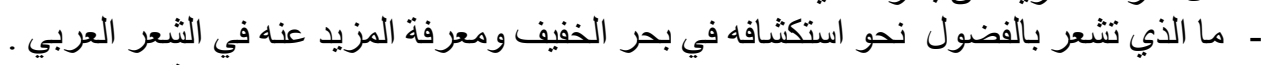
(10)

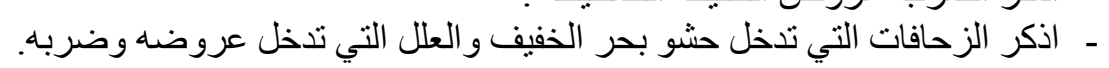

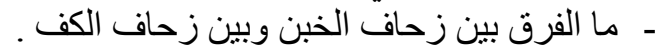

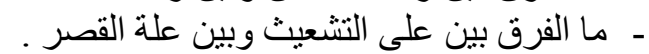

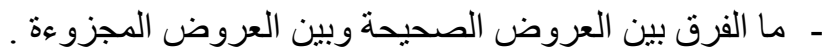

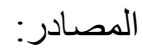
ـ ـ أمبو سعيدي، (2018) ، التدريس مداخله ، نماذجه، استر اتيجياته، دار المسيرة، للنشر و التوزيع والطباعة ،

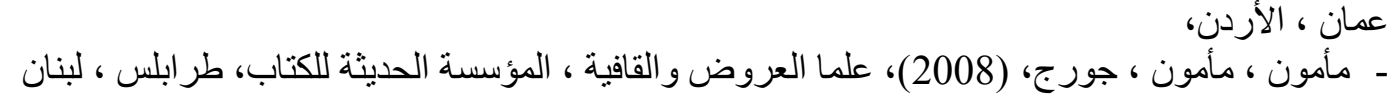

